\title{
Mass changes of the Greenland and Antarctic ice sheets and shelves and contributions to sea-level rise: 1992-2002
}

\author{
H. Jay ZWALLY, ${ }^{1}$ Mario B. GIOVINETTO, ${ }^{2}$ Jun $\mathrm{LI}^{2}{ }^{2}$ Helen G. CORNEJO, ${ }^{2}$ \\ Matthew A. BECKLEY, ${ }^{2}$ Anita C. BRENNER, Jack L. SABA, ${ }^{2}$ Donghui $\mathrm{YI}^{2}$ \\ ${ }^{1}$ Cryospheric Sciences Branch, Code 614.1, NASA Goddard Space Flight Center, Greenbelt, Maryland 20771, USA \\ E-mail: zwally@icesat2.gsfc.nasa.gov \\ ${ }^{2}$ SGT, Inc., Code 614.1, NASA Goddard Space Flight Center, Greenbelt, Maryland 20771, USA \\ ${ }^{3}$ Science Systems and Application, Inc., 10210 Greenbelt Road, Suite 600, Lanham, Maryland 20706, USA
}

\begin{abstract}
Changes in ice mass are estimated from elevation changes derived from 10.5 years (Greenland) and 9 years (Antarctica) of satellite radar altimetry data from the European Remote-sensing Satellites ERS-1 and -2. For the first time, the $\mathrm{d} H / \mathrm{d} t$ values are adjusted for changes in surface elevation resulting from temperature-driven variations in the rate of firn compaction. The Greenland ice sheet is thinning at the margins $\left(-42 \pm 2 \mathrm{Gta}^{-1}\right.$ below the equilibrium-line altitude (ELA)) and growing inland $\left(+53 \pm 2 \mathrm{Gt} \mathrm{a}^{-1}\right.$ above the ELA) with a small overall mass gain $\left(+11 \pm 3 \mathrm{Gt} \mathrm{a}^{-1} ;-0.03 \mathrm{~mm} \mathrm{a}^{-1} \mathrm{SLE}\right.$ (sea-level equivalent)). The ice sheet in West Antarctica (WA) is losing mass $\left(-47 \pm 4 \mathrm{Gt} \mathrm{a}^{-1}\right)$ and the ice sheet in East Antarctica (EA) shows a small mass gain $\left(+16 \pm 11 \mathrm{Gta}^{-1}\right)$ for a combined net change of $-31 \pm 12 \mathrm{Gt} \mathrm{a}^{-1}$ $\left(+0.08 \mathrm{~mm} \mathrm{a}^{-1} \mathrm{SLE}\right)$. The contribution of the three ice sheets to sea level is $+0.05 \pm 0.03 \mathrm{~mm} \mathrm{a}^{-1}$. The Antarctic ice shelves show corresponding mass changes of $-95 \pm 11 \mathrm{Gt} \mathrm{a}^{-1}$ in WA and $+142 \pm 10 \mathrm{Gt} \mathrm{a}^{-1}$ in EA. Thinning at the margins of the Greenland ice sheet and growth at higher elevations is an expected response to increasing temperatures and precipitation in a warming climate. The marked thinnings in the Pine Island and Thwaites Glacier basins of WA and the Totten Glacier basin in EA are probably icedynamic responses to long-term climate change and perhaps past removal of their adjacent ice shelves. The ice growth in the southern Antarctic Peninsula and parts of EA may be due to increasing precipitation during the last century.
\end{abstract}

\section{INTRODUCTION}

The mass balances of the Greenland and Antarctic ice sheets are of interest because of their complex linkage to climate variability and their direct effects on sea-level change. In recent decades, the spatial distribution of mass input and output data has greatly improved as field observations have been complemented by advances in remote sensing and dynamic modeling. Approximately $399 \mathrm{Gta}^{-1}$ of ice is accumulated on the Greenland ice sheet above the equilibrium line, and approximately $1637 \mathrm{Gta}^{-1}$ on the Antarctic ice sheet (modified from Giovinetto and Zwally, 2000; Zwally and Giovinetto, 2001), which is equivalent to the removal of $5.6 \mathrm{~mm} \mathrm{a}^{-1}$ from the oceans. The net mass balance is the difference between the mass input in the zone of net accumulation and the sum of the net ablation at the surface (including runoff), the direct discharge of ice into the ocean, and discharge of subglacial water across the grounding line. Uncertainties in previous mass-balance estimates $\left( \pm 53.0 \mathrm{Gta}^{-1}\right.$ for Greenland and $\pm 384 \mathrm{Gta}^{-1}$ for Antarctica (Huybrechts and others, 2001)) have been largely due to the difficulty of accurately measuring all the mass input and output fluxes (e.g. Rignot and Thomas, 2002).

Expected responses of the ice sheets to climate warming are both growth in thickness of the inland ice areas, due to increasing precipitation, and thinning near the margins, due to increasing surface melting (Huybrechts and others, 2001). In addition, dynamic ice thinning near the margins may be induced by processes such as removal or thinning of adjacent ice shelves or ice tongues (Thomas, 2003; Rignot and others, 2004; Scambos and others, 2004) as well as enhanced basal sliding due to surface meltwater reaching the ice-bedrock interface (Zwally and others, 2002c). Alley and others (2003) reviewed the state of knowledge of icesheet behavior from recent observational and modeling advances and suggested that the ice sheets may have a greater sensitivity to climate warming than previously considered.

Since the first results using altimeter surveys of ice-sheet elevation changes to estimate changes in ice volume and mass balance (Zwally, 1989), there has been an increasing use of altimetric measurements of elevation change $(\mathrm{d} H / \mathrm{d} t)$ to improve upon estimates from mass-flux studies. Recent results include the detection of significant thinning of the margins of the Greenland ice sheet, which was attributed to increases in both melting and dynamic thinning (Abdalati and others, 2001; Krabill and others, 2004), thickening of the EA ice sheet, attributed to increases in precipitation (Davis and others, 2005), and growth of the interior of Greenland (Johannessen and others, 2005). Nevertheless, a comprehensive assessment of the current mass balance of the ice sheets has not been made, due in part to the limited performances of satellite radar altimeters over the steeper ice-sheet margins and in part to limitations in the spatial and temporal coverage of airborne laser-altimeter surveys. Elevation changes are also caused by temporal variations in the rate of firn compaction (Zwally, 1989; Braithwaite, 1994; Arthern and Wingham, 1998; Zwally and Li, 2002), but corrections for this effect have not previously been made.

In this study, we extend the analysis of radar altimeter data from the two European Remote-sensing Satellites (ERS1 and -2) to $90.0 \%$ of the Greenland ice sheet, $77.1 \%$ of the Antarctic ice sheet and $81.8 \%$ of the Antarctic ice shelves. In Greenland, we use results of Airborne Topographic Mapper 

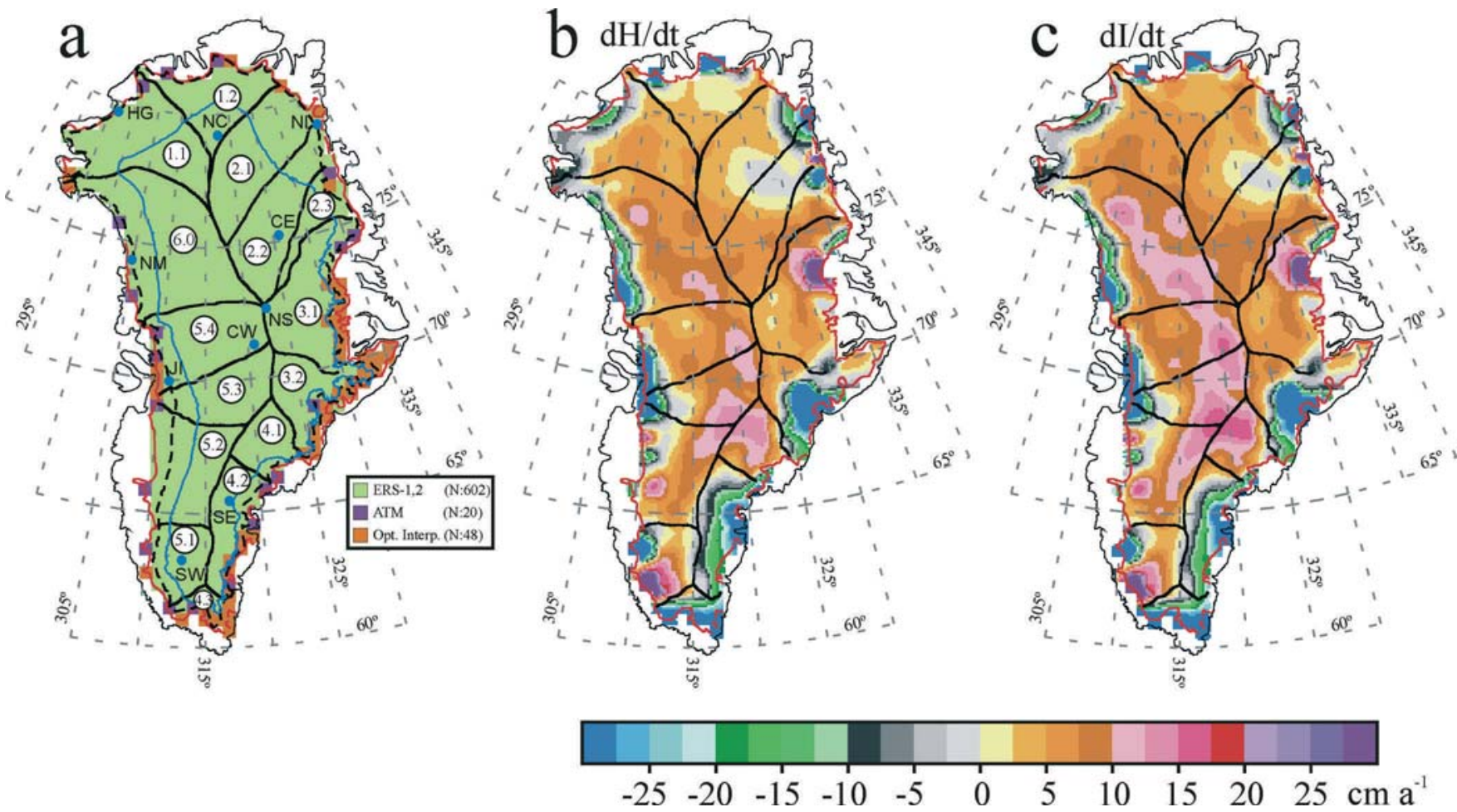

Fig. 1. Greenland. (a) Distribution of surface elevation change data by source, derived from ERS-1 and -2 radar altimetry, ATM (closestneighbor interpolation from airborne surveys), and obtained by optimal interpolation: ice terminus of coterminous ice sheet (red), equilibrium line (black dashes), $2000 \mathrm{~m}$ elevation contour (blue), drainage divides (black), drainage system designation (number in circles), and location of $H(t)$ series depicted in Figure 3a (labeled blue full circles). (b) Distribution of elevation change (dH/dt). (c) Distribution of icethickness change $(\mathrm{d} l / \mathrm{d} t)$.

(ATM) laser-altimeter surveys to increase coverage of the margins. We also use optimal-interpolation procedures to provide nearly complete spatial coverage of the ice sheets and shelves (Figs 1a and 2a). For the first time, we use a firn compaction model with a 20 year record of satellite-based surface temperatures to calculate corrections for elevation changes due to changes in the rate of firn compaction caused by temporal variations in firn temperature and nearsurface melting.

\section{OBSERVED AND INTERPOLATED ELEVATION CHANGES $(\mathrm{d} H / \mathrm{d} t)$}

Measurements of ice surface elevations $(H)$ from ERS- 1 and -2 radar altimeters are compiled as elevation time series, $H(t)$, from which elevation change $(\mathrm{d} H / \mathrm{d} t)$ values are derived (Fig. 3). The ERS altimeters operated in either ocean mode with a resolution of $45 \mathrm{~cm}$ per range gate or ice mode with a resolution of $182 \mathrm{~cm}$ per range gate. We use only ice mode data, because of a spatially variant bias between the modes and the greater spatial and temporal coverage of the ice mode data. We applied our V4 range-retracking algorithm, atmospheric range corrections, instrument corrections, slope corrections and an adjustment for solid tides (Zwally and Brenner, 2001). Instrument corrections include subtraction of a $40.9 \mathrm{~cm}$ bias from ERS-1 elevations to account for a different instrument parameter used for ERS-2 (Femenias, 1996) and corrections for drifts in the ultra-stable oscillator and bias changes in the scanning point target response that are obtained from the European Space Agency. We use the DUT DGM-E04 orbits, which have a radial orbit precision of 5-6 cm (Scharroo and Visser, 1998).
The time periods are from mid-April 1992 to mid-October 2002 for Greenland and to mid-April 2001 for Antarctica. The series are constructed for gridpoints nominally $50 \mathrm{~km}$ apart from sets of elevation differences measured at orbital crossovers using time periods of 91 days. Our methods enable us to obtain useful $H(t)$ series over more of the icesheet area than some other analyses have. For most gridpoints, crossovers within a $100 \mathrm{~km}$ circle centered on the gridpoint are used, and within $200 \mathrm{~km}$ for a few points. Crossover selection is also limited to elevations within $\pm 250 \mathrm{~m}$ of the elevation at the gridpoint center, which for slopes $>1 / 200$ restricts the selected areas to bands along elevation contours where the elevation changes tend to be spatially coherent. The first sequence of elevation differences at crossings between period $T_{1}$ and all successive $T_{i}$ is combined with the second sequence of those for crossings between $T_{2}$ and all successive $T_{i}$ and so forth for all additional sequences, which are then combined in one $H(t)$ (Zwally and Brenner, 2001). The resulting $H(t)$ series use all independent crossovers, including inter-satellite crossovers, which greatly increases the number of crossovers and the accuracy of the results (more crossovers and longer time intervals), as compared to using only the first sequence or only intra-satellite crossovers. For Greenland, we have $16 \times 10^{6}$ crossovers from ERS-1/ERS-1, $52 \times 10^{6}$ from ERS-2/ ERS-2, and $59 \times 10^{6}$ from ERS-1/ERS-2. For Antarctica, we have $157 \times 10^{6}$ crossovers from ERS-1/ERS-1, $276 \times 10^{6}$ from ERS-2/ERS-2, and $419 \times 10^{6}$ from ERS-1/ERS-2, whereas only crossovers from ERS-1/ERS-1 and ERS-2/ERS-2 are used by Davis and others (2005).

We obtain $\mathrm{d} H / \mathrm{d} t$ values for $602(90 \%)$ of the 670 gridpoints on Greenland ice and 4085 (79\%) of the 5175 
gridpoints on Antarctic ice, i.e. $77 \%$ of the grounded points and $82 \%$ of the floating points (Table 1). The distance between points in our nominal $50 \mathrm{~km}$ grid, which is mapped in a polar stereographic projection with plane tangent at the pole, ranges between $48.784 \mathrm{~km}$ at $60^{\circ}$ and $52.286 \mathrm{~km}$ at $90^{\circ}$. In Greenland, the coterminous ice-sheet area is sampled by 670 gridpoints, excluding islands and ice caps not attached by ice (Fig. 1b). The area of Antarctica is sampled by 5238 gridpoints, excluding islands not attached by ice (Fig. 2b). The working grid is reduced to $N=5175$ by excluding the relatively small areas of grounded ice in Graham Land and grounded and floating ice in eastern Palmer Land, for which it is not possible to assemble reliable $H(t)$ series. Of the 5175 gridpoints used, 4606 are on grounded ice (coterminous ice sheet, islands attached by ice, and ice rises) and 569 are on floating ice (ice shelves and ice tongues). East Antarctica (EA) and West Antarctica (WA) are divided on the basis of ice provenance (Fig. 2) rather than the traditional boundary along the Transantarctic Mountains (Zwally and others, 2002b).

Although the ERS-1 and -2 altimeters are nearly identical, a significant inter-satellite elevation bias was measured over the ice sheets during the 13 months of simultaneous operation from May 1995 through May 1996. The ERS-1/ ERS-2 bias does not occur over the oceans nor on some of the flat ice surfaces. Although the bias tends to be correlated with each of three interrelated parameters (received backscatter power, surface slope and surface elevation), it was not possible to formulate the bias as a consistent function of these parameters over all of the ice sheet and ice shelves. Therefore, for Antarctica, we averaged the measured biases at crossovers between ERS- 1 and ERS-2 on a $50 \mathrm{~km}$ grid and smoothed the averages over five gridpoints with a linear weighting with distance from the center. For Greenland, we averaged the crossover differences on a $50 \mathrm{~km}$ grid using crossovers within $400 \mathrm{~km}$ and a restriction to elevations within $\pm 250 \mathrm{~m}$ of the gridpoint, giving a smoothing similar to that for Antarctica.

The applied bias correction lowers the ERS-2 elevations by an average of $30.7 \mathrm{~cm}$ with standard deviation $(\mathrm{SD})=$ $20.9 \mathrm{~cm}$ spatial variation over Greenland, by $17.5 \mathrm{~cm}$ with $\mathrm{SD}=13.3 \mathrm{~cm}$ over Antarctic grounded ice, and by $12.0 \mathrm{~cm}$ with $\mathrm{SD}=9.6 \mathrm{~cm}$ over Antarctic floating ice. Over Greenland, the bias correction lowers the average $\mathrm{d} H / \mathrm{d} t$ by roughly $3.5 \mathrm{~cm} \mathrm{a}^{-1}$. Over Antarctica, the correction lowers the average $\mathrm{d} H / \mathrm{d} t$ by $2.4 \mathrm{~cm} \mathrm{a}^{-1}$ with $\mathrm{SD}=1.7 \mathrm{~cm} \mathrm{a}^{-1}$ on grounded ice and by $1.6 \mathrm{~cm} \mathrm{a}^{-1}$ with $\mathrm{SD}=1.2 \mathrm{~cm} \mathrm{a}^{-1}$ on floating ice. The effects of the bias correction on calculations of mass change $(\mathrm{d} M / \mathrm{d} t)$ for the ERS gridpoints are roughly $-50 \mathrm{Gta}^{-1}$ for Greenland and $-205 \mathrm{Gta}^{-1}$ for Antarctica, indicating the importance of this correction. For Greenland, Johannessen and others (2005) used a different method to calculate the bias, and state 'the calculated spatially averaged ERS-1/ERS-2 bias is $21.5 \pm 2.0 \mathrm{~cm}^{\prime}$, which may be smaller than our $30.7 \mathrm{~cm}$ because we include more lowerelevation gridpoints. They also state the effect on $\mathrm{dH} / \mathrm{dt}$ varies from typically $\sim 2 \mathrm{~cm} \mathrm{a}^{-1}$ over the interior plateau to about $20 \mathrm{~cm} \mathrm{a}^{-1}$ over the ... margins (presumably negative values), which spans our average $-3.5 \mathrm{~cm} \mathrm{a}^{-1}$. Davis and others (2005) in effect apply a bias correction by calculating separate $H(t)$ series for ERS- 1 and ERS-2 and adjusting them together during the 12 month overlap period, but do not state the magnitude of their adjustments.
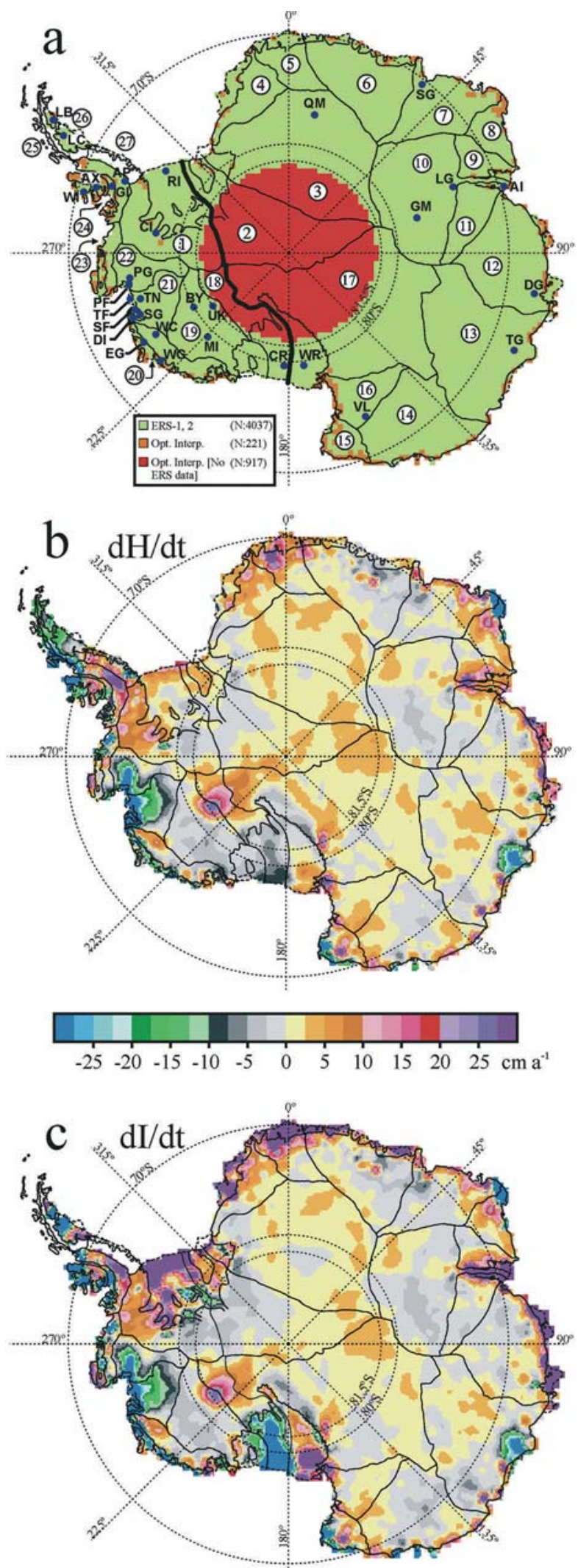

Fig. 2. Antarctica. (a) Distribution of surface elevation change data by source, derived from ERS- 1 and -2 radar altimetry and obtained by optimal interpolation: coast and grounding line (black, heavy), ice-shelf front (black dashes), drainage divides (black, thin) of which the wider trace depicts the WA/EA divide by ice provenance, drainage system designation (number in circles), and location of $H(t)$ series depicted in Figure $3 \mathrm{~b}$ (labeled blue full circles). Excluded from this study: whole area of system 25, grounded-ice area in 26, and grounded- and floating-ice areas in 27. (b) Distribution of elevation change $(\mathrm{d} / \mathrm{H} / \mathrm{d} t)$. (c) Distribution of ice-thickness change $(\mathrm{d} / / \mathrm{d} t)$. 


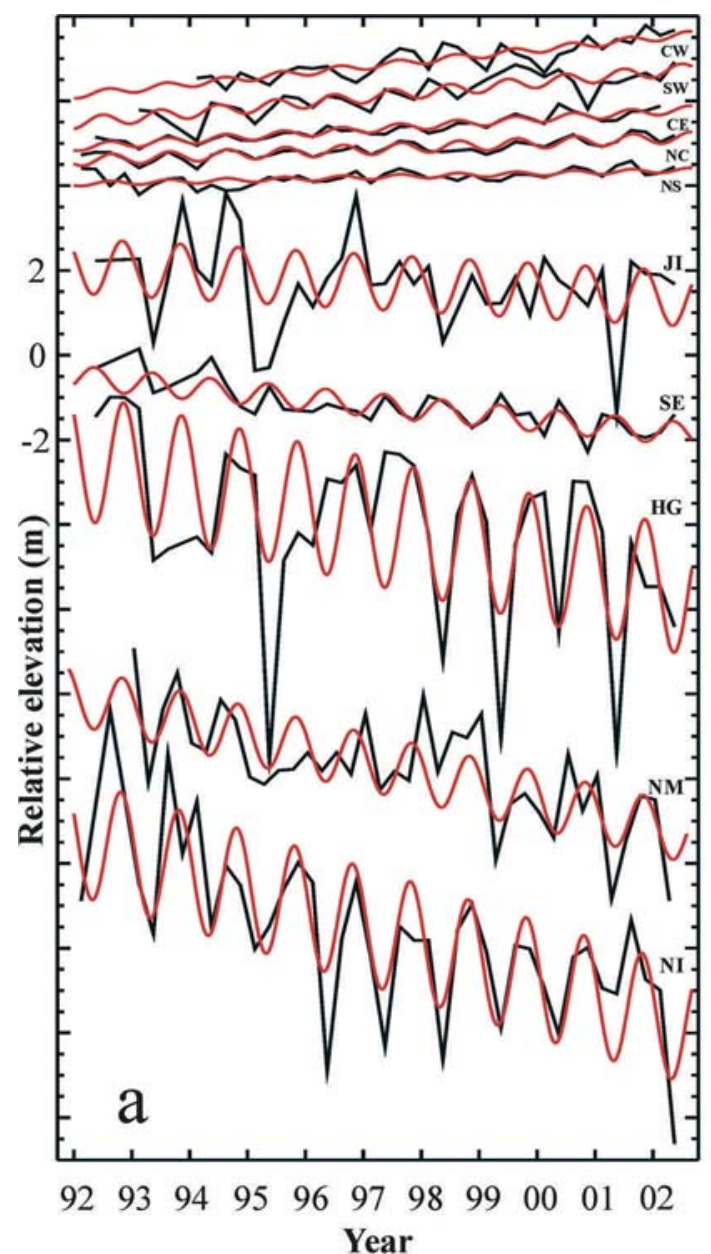

Fig. 3. $H(t)$ series (black) and multi-parameter linear-sinusoidal function (red), labeled same as locations shown in Figures $1 \mathrm{a}$ and $2 \mathrm{a}$ and listing site elevation in meters, and derived $\mathrm{d} H / \mathrm{d} t \pm \sigma_{\mathrm{s}}$ in $\mathrm{cm} \mathrm{a}^{-1}$. Crossovers within $100 \mathrm{~km}$ circle of location are used except within $50 \mathrm{~km}$ for PG2. (a) Greenland: CW (central west), 3087, $+13.5 \pm 1.6$; SW (southwest), 2456, $+12.0 \pm 1.7$; CE (central east), $2700,+8.4 \pm 0.5 ; \mathbf{N C}$ (north central), $2314,+5.2 \pm 0.5$; NS (near Summit), 3225, +3.0 \pm 0.8 ; JI (Jakobshavn Isbræ), 1316, $-7.4 \pm 5.4$; SE (southeast), 2173, $-12.7 \pm 1.7$; HG (Humboldt Glacier), 472, $-30.6 \pm 8.8$; NM (north margin), $1365,-30.7 \pm 5.1$; NI ('Northeast Greenland Ice Stream'), 614, $-42.2 \pm 6.2$. (b) Antarctica: AP (Antarctic Peninsula), 1832, +35.7 \pm 3.9 ; UK (upper Kamb Ice Stream), 941, +25.9 $\pm 1.1 ; \mathbf{C l}$ (Carlson Inlet), 271, +23.0 $\pm 2.5 ; \mathbf{A X}$ (Alexander Island), 688, +21.2 $\pm 3.0 ;$ Al (Amery Ice Shelf), 49, $+15.0 \pm 1.7 ;$ WR (western Ross Ice Shelf), 52, $+8.6 \pm 0.6$; WC (West Antarctica - coastal), $1734,+6.8 \pm 1.3 ;$ RI (Ronne Ice Shelf), 54, $+5.3 \pm 2.7$; VL (Victoria Land), 2297, $+5.3 \pm 1.1$; DM (Dronning Maud Land), 3104, +3.9 \pm 0.7 ; BY (Byrd Station), 1524, $-1.2 \pm 0.7$; GM (Gamburtsev Mountains), 3074, $-4.1 \pm 0.7$; MI (MacAyeal Ice Stream), 682, $-7.2 \pm 1.1 ; \mathbf{C R}$ (central Ross Ice Shelf), 52, $-9.4 \pm 1.2$; UL (upper Lambert Glacier), 1068, $-11.4 \pm 1.3$; SH (Shirase Glacier), 1160, $-11.6 \pm 3.8$; LC (Larsen C ice shelf), 42, $-17.9 \pm 1.8$; LB (Larsen B ice shelf), 28, $-20.4 \pm 2.0$; DG (Denman Glacier), 1161, $-20.6 \pm 5.0 ;$ GI (George VI Ice Shelf), 51, $-21.0 \pm 1.6$; WI (Wilkins Ice Shelf), 27, $-24.5 \pm 2.7$; WG (west Getz Ice Shelf), 45, $-27.6 \pm 2.0$; TF (Thwaites Glacier Tongue), 40, $-31.4 \pm 2.9$; PF (Pine Island Glacier Tongue), 68, $-35.3 \pm 2.3$; TG (Thwaites Glacier), 774, $-42.2 \pm 3.0$; EG (east Getz Ice Shelf), 93, $-42.4 \pm 2.6$; TN (Totten Glacier), 866, $-44.8 \pm 4.8$; SF (Smith Glacier Tongue), 52, $-60.5 \pm 3.2$; PG2 (Pine Island Glacier), 627, $-68.9 \pm 3.4$; PG (Pine Island Glacier), 323, $-87.9 \pm 5.7$; SG (Smith Glacier), $407,-261.8 \pm 7.5$ (for this site only, note factor of 3 ).

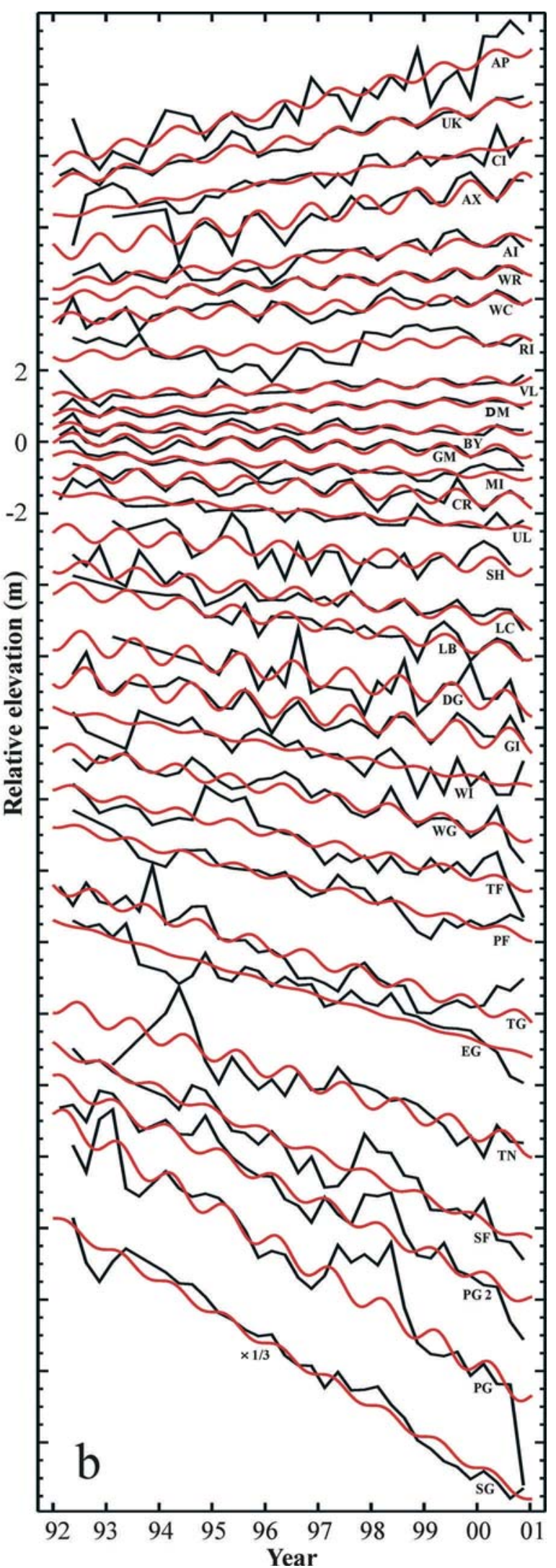


Table 1. Mean values and errors of terms $(\mathrm{d} H / \mathrm{d} t, \mathrm{~d} C / \mathrm{d} t, \mathrm{~d} B / \mathrm{d} t, \mathrm{~d} S / \mathrm{d} t)$ used in the estimate of ice-thickness change $(\mathrm{d} l / \mathrm{d} t)$ for areas of Greenland and West and East Antarctica defined by ice provenance, listing net mass balance $(\mathrm{d} F / \mathrm{d} t, \mathrm{~d} M / \mathrm{d} t)$ and sea-level contribution (SLE). All values are listed as computed to allow tracing of estimates in other columns (some second and third decimals are not significant); small differences are due to use of round-off values

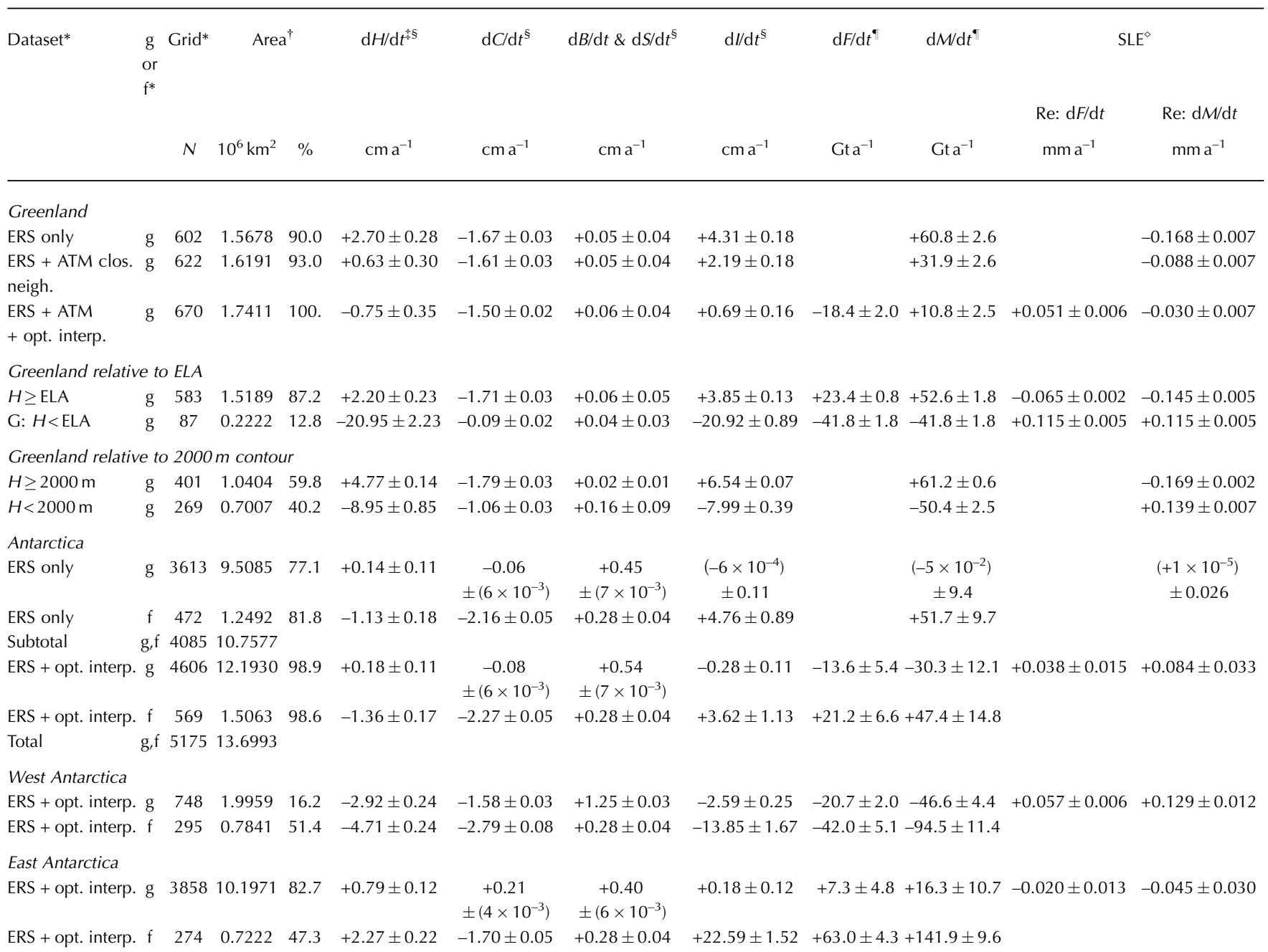

All ice sheets

Grand total $\quad \mathrm{g} \quad 13.934199 .0$ (Sum of Greenland $(\mathrm{g}, \mathrm{N}=670) \&$ Antarctica $(\mathrm{g}, \mathrm{N}=4606) \rightarrow-32.0 \pm 5.8-19.5 \pm 12.4+0.088 \pm 0.016+0.054 \pm 0.034$

*The coterminous ice sheet in Greenland is sampled by 670 gridpoints of which 583 lie above the equilibrium-line altitude (ELA); all gridpoints are considered to sample grounded ice (g). Antarctica, excluding islands not attached by ice, is sampled by 5238 gridpoints; of these, DS25 ( $N=14(\mathrm{~g}))$, DS26 ( $N=19(\mathrm{~g}))$ and DS27 $(\mathrm{N}=30(22(\mathrm{~g}), 8$ floating ice $(\mathrm{f})))$ are excluded from the study.

${ }^{\dagger}$ For Antarctica, the sampled area \% is relative to totals of sampled plus unsampled areas: $N=5238,13.8603 \times 10^{6} \mathrm{~km}^{2} ; \mathrm{N}=4661(\mathrm{~g}), 12.3332 \times 10^{6} \mathrm{~km}{ }^{2}$; $N=577(\mathrm{f}), 1.5270 \times 10^{6} \mathrm{~km}^{2}$.

The $\mathrm{d} H / \mathrm{d} t$ error $\equiv \sigma_{\mathrm{s}}$ statistic which includes the seasonal and annual variability of accumulation (see text).

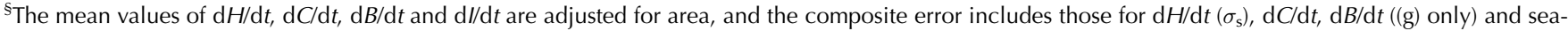
level rise $(\mathrm{d} S / \mathrm{d} t$, (f) only); estimates for floating ice are factored by the freeboard ratio (Fb; mean value $=6.62$; see text).

'Conversions to mass for $\mathrm{d} / \mathrm{d} t$ use a factor of 0.4 for firn at $400 \mathrm{~kg} \mathrm{~m}^{-3}$ except in the net ablation zone of Greenland $\left(0.9\right.$ for ice at $\left.900 \mathrm{~kg} \mathrm{~m}{ }^{-3}\right)$, and for $\mathrm{d} / \mathrm{M} / \mathrm{d} t$ use factors of 0.9 for $(\mathrm{g})$ and 0.87 for $(\mathrm{f})$ at $870 \mathrm{~kg} \mathrm{~m}^{-3}$.

-Sea-level equivalent of $362 \mathrm{Gt} \mathrm{mm}^{-1}\left(\mathrm{Gt}=\mathrm{km}^{3}\right.$ water) allows for area of estuaries, ice shelves and tidal marshes.

Another significant correction is applied for the dependence of the height measured by the altimeter on the received backscatter power similar to those applied in preceding studies (Wingham and others, 1998; Davis and others, 2005). We derive a spatially variant sensitivity $(\mathrm{d} H / \mathrm{d} G)$ of the measured height $(H)$ to changes in the measured backscattered power using the value of the automatic gain control (AGC) as the measure of the backscattered power $(G)$. We first construct $G(t)$ time series at each gridpoint using the same procedure as for the $H(t)$ series. For each gridpoint, we correlate the $N$ values of $H_{i}\left(t_{i}\right)$ and $G_{i}\left(t_{i}\right)$ and calculate a linear fit, $H=H_{0}+(\mathrm{d} H / \mathrm{d} G) G$ and the correlation coefficient $(R)$.
The corrected elevation series is then $H_{c i}=H_{i}-(\mathrm{d} H /$ $\mathrm{d} G)\left(G_{i}-G_{0}\right)$, where $G_{0}=-H_{0}(\mathrm{~d} H / \mathrm{d} G)^{-1}$. The sensitivity factor $(\mathrm{d} H / \mathrm{d} G)$ of the elevation to the backscatter is correlated with $R$, so for smaller values of $R$ the magnitudes of the sensitivity and the correction decrease. Where the absolute value of $R$ is $<0.2$, no backscatter correction is applied, because the correlation and sensitivity are both small. Where $\mathrm{d} H / \mathrm{d} G<-0.2 \mathrm{~m} \mathrm{~dB}^{-1}$, it is limited to $-0.2 \mathrm{~m} \mathrm{~dB}^{-1}$, and where $\mathrm{d} H / \mathrm{d} G>0.7 \mathrm{~m} \mathrm{~dB}^{-1}$ it is limited to $0.7 \mathrm{~m} \mathrm{~dB}^{-1}$ to limit a few outlying values with poorer statistics.

The average effect of the backscatter correction on $\mathrm{d} H / \mathrm{d} t$ is small, but local corrections can be large. For example, at 
Byrd Station $\left(80^{\circ} \mathrm{S}, 120^{\circ} \mathrm{W}\right)$, the $\mathrm{d} H / \mathrm{d} G$ is $0.40 \mathrm{~m} \mathrm{~dB}^{-1}, R$ is 0.90 , and the range of $G$ variation is $3.2 \mathrm{~dB}$ with a strong seasonal cycle. The uncorrected $\mathrm{d} H / \mathrm{d} t$ is $5.4 \pm 1.3 \mathrm{~cm} \mathrm{a}^{-1}$ with a seasonal amplitude of $64 \mathrm{~cm}$ peak-to-peak, and the corrected $\mathrm{d} H / \mathrm{d} t$ is $-1.2 \pm 0.7 \mathrm{~cm} \mathrm{a}^{-1}$ with a smaller seasonal amplitude of $24 \mathrm{~cm}$. Generally, the backscatter correction appears to remove noise and significantly improve the regularity of the seasonal cycle. In Greenland, the mean correction applied to $\mathrm{d} H / \mathrm{d} t$ is only $-0.02 \mathrm{~cm} \mathrm{a}^{-1}$ with a $2.36 \mathrm{~cm} \mathrm{a}^{-1} \mathrm{SD}$ spatial variation. In Antarctica, the mean correction is $-0.34 \mathrm{~cm} \mathrm{a}^{-1}$ with a $2.94 \mathrm{~cm} \mathrm{a}^{-1} \mathrm{SD}$ spatial variation on grounded ice and $-0.13 \mathrm{~cm} \mathrm{a}^{-1}$ with a $2.52 \mathrm{~cm} \mathrm{a}^{-1} \mathrm{SD}$ spatial variation on floating ice. The approximate effects on calculations of mass change $(d M / d t)$ for the ERS gridpoints are $-1.5 \mathrm{Gt} \mathrm{a}^{-1}$ for Greenland and $-32 \mathrm{Gt} \mathrm{a}^{-1}$ for Antarctica.

A multi-parameter linear-sinusoidal function is fitted to the $H(t)$ series to obtain linear trends of $\mathrm{d} H / \mathrm{d} t$, while accounting for seasonal variations in the elevation measurement (Fig. 3). The frequency of the sine function is fixed at 1 year. The fit calculates the slope $(\mathrm{d} H / \mathrm{d} t)$, intercept, phase (e.g. the date of minimum) and the amplitude of the seasonal cycle with standard deviations of each parameter. In most $H(t)$ series, the linear-sinusoidal model represents the data very well. The standard deviation $\left(\sigma_{\mathrm{s}}\right)$ of the linear slope $(\mathrm{d} H / \mathrm{d} t)$ obtained from the multi-parameter fitting is used as the estimate of the error in the derived $\mathrm{d} H / \mathrm{d} t$ trends. The $\sigma_{\mathrm{s}}$ are affected by departures of the slope from the model representation of a linear trend and a seasonal sinusoidal variation, as well as by the measurement errors in $H_{i}\left(t_{i}\right)$. Such departures may include unmodeled temporal variability due to short-term variability of the accumulation rate or other factors. Therefore, the $\sigma_{\mathrm{s}}$ provide estimates of the errors that include effects of natural variability in the elevation, which we carry through to estimates of the mass balance. Alternatively, Davis and others (2005) use an 'autoregression' technique (Ferguson and others, 2004) to match non-linear variations of the seasonal cycle and interannual variability, which in general tends to reduce the $\sigma_{\mathrm{s}}$ of the linear term. We believe it is more appropriate for the unmodeled variability to be represented in $\sigma_{\mathrm{s}}$ giving a larger error estimate. Also, removing interannual variability can lead to a linear trend that does not accurately represent the change during the period of the measurements. Maps of our $\sigma_{\mathrm{s}}$ including an optimal interpolation of $\sigma_{\mathrm{s}}$ with a factor that increases with the distance of interpolation, are shown in the Appendix (Fig. 7).

The $\mathrm{d} H / \mathrm{d} t$ at Byrd Station (BY in Figs 2a and $3 \mathrm{~b}$ ), for example, is $-1.2 \pm 0.7 \mathrm{~cm} \mathrm{a}^{-1}$, which is comparable to a global positioning system-based measurement (Hamilton and others, 1998) of $-0.4 \pm 2.2 \mathrm{~cm} \mathrm{a}^{-1}$ within the range of errors. Adjusting our $\mathrm{d} H / \mathrm{d} t$ for firn-compaction $(\mathrm{d} C / \mathrm{d} t=$ $\left.-0.7 \mathrm{~cm} \mathrm{a}^{-1}\right)$ and bedrock motion $\left(\mathrm{d} B / \mathrm{d} t=+1.7 \mathrm{~cm} \mathrm{a}^{-1}\right)$ gives an ice thinning rate of $2.2 \mathrm{~cm} \mathrm{a}^{-1}$, which compares well with the thinning rate of $3 \mathrm{~cm} \mathrm{a}^{-1}$ from field measurements of ice flow and mass-continuity calculations (Whillans, 1977). In contrast, a region about $175 \mathrm{~km}$ to the southwest and inland of Kamb Ice Stream has large elevation increases (e.g. $\mathrm{d} H / \mathrm{d} t=+25.9 \pm 1.1 \mathrm{~cm} \mathrm{a}^{-1}$ at point $U K$ in Figs $2 \mathrm{a}$ and $3 \mathrm{~b}$ ).

The distributions of $\mathrm{d} H / \mathrm{d} t$ are shown in Figures $1 \mathrm{~b}$ and $2 \mathrm{~b}$, and descriptive statistics are listed in Table 1. We utilize ATM results (Abdalati and others, 2001) from 1993 to 1999 and closest-neighbor interpolation to obtain $\mathrm{d} H / \mathrm{d} t$ values for an additional $3 \%$ of the area of Greenland. We use the optimal interpolation method of kriging with default options in the Golden Software Inc. Surfer ${ }^{\mathbb{R}}$ (version 7.0) computer program to provide nearly complete spatial coverage $(100 \%$ of the coterminous grounded-ice area of Greenland and $99 \%$ of each of the grounded- and floating-ice areas of Antarctica). The grounded and floating areas of Antarctica are interpolated separately and merged. Most of the interpolated points are widely distributed over the steeper coastal areas of the ice sheets, except for the area of Antarctica south of $81.5^{\circ} \mathrm{S}$ (Fig. 2a and b). The observed $\mathrm{d} H / \mathrm{d} t$ along the $81.5^{\circ} \mathrm{S}$ perimeter of the interpolated area are mostly small (i.e. -5 to $+5 \mathrm{~cm} \mathrm{a}^{-1}$ ), except for the region of large increases south of point UK in WA. The average $\mathrm{d} H / \mathrm{d} t$ on grounded ice in the area south of $81.5^{\circ} \mathrm{S}$ is $+1.6 \mathrm{~cm} \mathrm{a}^{-1}$, and the calculated average ice thickness and mass changes are relatively small $\left(\mathrm{d} l / \mathrm{d} t=+0.64 \mathrm{~cm} \mathrm{a}^{-1}\right.$ and $\left.\mathrm{d} M / \mathrm{d} t=+14 \mathrm{Gt} \mathrm{a}^{-1}\right)$.

\section{CALCULATION OF ICE-THICKNESS CHANGES} $(\mathrm{d} l / \mathrm{d} t)$

Deriving ice-thickness changes $(\mathrm{d} / / \mathrm{d} t)$ from $\mathrm{d} H / \mathrm{d} t$ values requires correction for elevation changes $(\mathrm{d} C / \mathrm{d} t)$ induced by temporal variations in the rate of firn compaction, and adjustment for vertical motion of the underlying bedrock $(\mathrm{d} B / \mathrm{d} t)$ or sea level $(\mathrm{dS} / \mathrm{dt})$. Over grounded ice, the thickness change is

$$
\left(\frac{\mathrm{d} I}{\mathrm{~d} t}\right)_{\mathrm{g}}=\frac{\mathrm{d} H}{\mathrm{~d} t}-\frac{\mathrm{d} C}{\mathrm{~d} t}-\frac{\mathrm{d} B}{\mathrm{~d} t} .
$$

We use the radial components $(\mathrm{d} B / \mathrm{d} t)$ of three models of isostatic rebound (from Ivins and others, 2001; Huybrechts, 2002; Peltier, 2004), labeled $(\mathrm{d} B / \mathrm{d} t)_{\mathrm{I}, \mathrm{H}, \mathrm{P}}$ respectively, interpolated to our gridpoints. The model of Ivins and others (2001) is global and covers Greenland, although the referenced work is limited to Antarctica. The averages (Fig. 8 in Appendix) are weighted to account for distributions that showed similar patterns, i.e. for Greenland $\mathrm{d} B / \mathrm{d} t=$ $1 / 4(\mathrm{~d} B / \mathrm{d} t)_{\mathrm{P}}+1 / 4(\mathrm{~d} B / \mathrm{d} t)_{\mathrm{H}}+1 / 2(\mathrm{~d} B / \mathrm{d} t)_{1}$, and for Antarctica $\mathrm{d} B / \mathrm{d} t=1 / 4(\mathrm{~d} B / \mathrm{d} t)_{1}+1 / 4(\mathrm{~d} B / \mathrm{d} t)_{\mathrm{P}}+1 / 2(\mathrm{~d} B / \mathrm{d} t)_{\mathrm{H}}$. The $\mathrm{d} B / \mathrm{d} t$ errors are estimated at $\pm 1 / 2$ of the range from the average of the two results with similar patterns to the third model result.

On floating ice, the change in thickness is

$$
\left(\frac{\mathrm{d} I}{\mathrm{~d} t}\right)_{\mathrm{f}}=\mathrm{Fb}\left(\frac{\mathrm{d} H}{\mathrm{~d} t}-\frac{\mathrm{d} C}{\mathrm{~d} t}-\frac{\mathrm{d} S}{\mathrm{~d} t}\right)
$$

where $\mathrm{Fb}$ is the freeboard ratio of total thickness to freeboard height (ice surface elevation above sea level). The Fb value for each gridpoint is determined from buoyancy using $\mathrm{Fb}=\rho_{\mathrm{w}} /\left(\rho_{\mathrm{w}}-\rho_{\mathrm{if}}\right)$, where $\rho_{\mathrm{w}}=1028.5 \mathrm{~kg} \mathrm{~m}^{-3}$ is the density of Antarctic Shelf Water (Whitworth and others, 1998) and $\rho_{\text {if }}$ is the mean density of the floating-ice column. We iteratively calculate ice thickness and $\rho_{\text {if }}$ values for each gridpoint to account for the dependence of $\rho_{\text {if }}$ on thickness. The resulting mean ice thickness of the Antarctic ice shelves $(\mathrm{N}=569)$ is $488 \mathrm{~m}(\mathrm{SD}=313 \mathrm{~m})$, the mean $\rho_{\text {if }}$ is $870 \mathrm{~kg} \mathrm{~m}^{-3}$ $\left(\mathrm{SD}=28 \mathrm{~kg} \mathrm{~m}^{-3}\right)$ and the mean $\mathrm{Fb}$ is $6.62(\mathrm{SD}=0.89)$. We use $\mathrm{d} S / \mathrm{d} t=2.8 \pm 0.4 \mathrm{~mm} \mathrm{a}^{-1}$ for contemporaneous sea-level rise (Leuliette and others, 2004).

The $\mathrm{d} C / \mathrm{d} t$ values (Fig. 9 in Appendix) are calculated for each gridpoint with an enhanced firn compaction model that is sensitive to variations in firn temperature and surface 
melting, obtained from a 20 year record of surface temperatures from satellite infrared observations. The firn compaction model ( $\mathrm{Li}$ and Zwally, 2002; Zwally and Li, 2002 ) is augmented by inclusion of the effects of vapor transport in the firn (Li and Zwally, 2004) and the effects of near-surface melting. The model uses a temperaturedependent activation energy and has greater sensitivity and a more rapid compaction response to variations in temperature than other models (e.g. Arthern and Wingham, 1998). The model produces seasonal variations in the rate of densification, seasonal variations in density with depth, and seasonal changes in surface elevation that are generally consistent with observations (Li and Zwally, 2002, 2004; Zwally and Li, 2002; Li and others, 2003; Dibb and Fahnestock, 2004). Surface melting and refreezing is included by using an empirical melting-temperature model (Braithwaite and Zhang, 2000), which gives melting when the monthly average temperature is $>-8^{\circ} \mathrm{C}$, and the corresponding changes in density are calculated. A similar treatment of the effect of melting on densification is given in Reeh and others (in press). The mean accumulation rates are held constant with time in the model, since the intent is to calculate temperature-dependent variations in surface elevation and not variations caused by variability in accumulation rates, which are discussed in the next section.

The model is driven with the latest available data of monthly surface temperatures (Comiso, 2003; Comiso and Parkinson, 2004) for 1982-2003 from satellite-borne Advanced Very High Resolution Radiometers. The temperature data for the Greenland ice sheet have been improved from the early version of the dataset by a recalibration using more ground-station data of surface temperature. A steadystate 1 year monthly temperature cycle determined as the average of the first 3 years (1982-84) of temperature data, with constant accumulation $(A)$ and surface firn density of 0.3 , is used to establish the initial steady-state density profile with depth. The surface height variation $C(t)$ is calculated from 1982 to 2003 and $\mathrm{d} C / \mathrm{d} t$ is obtained by a linear fit to the $C(t)$ for the time period of the $H(t)$ and derived $\mathrm{d} H / \mathrm{d} t$. We use an error estimate of $\pm 30 \%$ on the calculated $\mathrm{d} C / \mathrm{d} t$, which is approximately equivalent to the range of error that would be induced by $\pm 25 \%$ errors in the temperature anomalies.

In general, warmer temperatures increase the rate of compaction and lower the surface elevation, whereas colder temperatures raise the surface elevation. Near-surface melting and subsequent refreezing in the firn also lowers the surface by changing firn to higher-density ice, which in turn affects the rate of subsequent densification. Although much of the densification in the upper firn layers occurs during the warmer summer months, temperature anomalies in winter also have a large impact on the rate of densification during summer, because of their preconditioning effect on the summer firn temperatures.

In Greenland, the calculated $\mathrm{d} C / \mathrm{d} t$ values are mostly negative, showing primarily the effect of a positive trend in winter temperatures as well as the increase in summer melting during the 1990s. The average $\mathrm{d} C / \mathrm{d} t$ over the accumulation zone is $-1.71 \mathrm{~cm} \mathrm{a}^{-1}$, indicating an average surface lowering from an increased rate of compaction. Without adjustment for $\mathrm{d} C / \mathrm{d} t$, this surface lowering might be incorrectly interpreted as a mass loss of $23.4 \mathrm{Gta}^{-1}$ (using an average column ice density of 0.9 ). In WA, the average $\mathrm{d} C / \mathrm{d} t$ for grounded ice is $-1.58 \mathrm{~cm} \mathrm{a}^{-1}$ (28.4 Gt a $\mathrm{a}^{-1}$ equivalent) and on the floating ice is $-2.79 \mathrm{~cm} \mathrm{a}^{-1}$ (130 Gta $\mathrm{G}^{-1}$ equivalent). These surface lowerings in WA are caused by a regional warming trend, including melting effects on the ice shelves and in some coastal areas. In EA, the average $\mathrm{d} C / \mathrm{d} t$ on the grounded ice is $+0.21 \mathrm{~cm} \mathrm{a}^{-1}$ ( $-19.3 \mathrm{Gta}^{-1}$ equivalent), with the largest increases around $135^{\circ} \mathrm{E}$ within a few hundred $\mathrm{km}$ of the coast. The small increase in EA is due to the small cooling trend over much of the region. On the floating ice in $\mathrm{EA}$, the average $\mathrm{d} C / \mathrm{d} t$ is $-1.70 \mathrm{~cm} \mathrm{a}^{-1}\left(73.2 \mathrm{Gta}^{-1}\right.$ equivalent), which is due to warming and melting of the ice shelves indicated by the temperature record.

Our calculated $\mathrm{d} / / \mathrm{d} t$ for Greenland and Antarctic subregions are listed in Table 1 and shown in Figures 1c and 2c. The data are weighted for small differences in the area of the grid squares in the polar stereographic map projection. Values for each drainage system (DS) are listed in Table 2 and shown in Figure 4a.

\section{ESTIMATION OF MASS CHANGES $(\mathrm{d} M / \mathrm{d} t)$}

The mass change $(d / / d t)$ associated with $d / / d t$ depends on whether the change in thickness of the firn/ice column is caused by the ice dynamics not being in balance with the long-term (multi-decadal) accumulation rate or is caused by shorter-term (decadal) variability in accumulation rate $(A(t))$. Separating components of $\mathrm{d} l / \mathrm{d} t$ gives

$$
\frac{\mathrm{d} M}{\mathrm{~d} t}=\rho_{\text {ice }}\left[\delta\left(\frac{\mathrm{d} /}{\mathrm{d} t}\right)_{\mathrm{NStS}}+\left(\frac{\mathrm{d} /}{\mathrm{d} t}\right)_{\mathrm{StS}}+\left(\frac{\mathrm{d} /}{\mathrm{d} t}\right)_{\operatorname{In}}-\left(\frac{\mathrm{d} /}{\mathrm{d} t}\right)_{\text {Out }}\right] \mathrm{Ar},
$$

where $\rho_{\text {ice }}=0.917$ is the density of ice (i.e. relative to water) and Ar is the area of the firn/ice column. In the first term, $(\mathrm{d} l / \mathrm{d} t)_{\mathrm{NStS}}$ is the change in thickness due to any nonsteady-state (NStS) change in firn thickness from short-term changes in $A(t)$ and/or temperature $(T(t))$. The factor $\delta$ can range from about 0.33 to 1 if the rate of firn compaction is not in steady state with the surface mass input. The term $\rho_{\text {ice }} \delta$ may be considered as the effective density of the NStS component of the mass change. In steady state the velocity of firn compaction is constant, the density profile with depth is not changing and the flux of lower-density firn input at the surface is equal to the downward flux of ice at depth $(\delta=1$ and $\left.(\mathrm{d} l / \mathrm{d} t)_{\mathrm{NStS}}=0\right)$. In the ablation zone, the first term is zero, neglecting the seasonal effect of winter snow cover. The second term in Equation (3) is due to the steady-state (StS) component of the mass added at the surface, and $\rho_{\text {ice }}(\mathrm{d} l / \mathrm{d} t)_{\text {StS }}$ is equal to the long-term average accumulation rate $(A)$. The third and fourth terms are due to the average horizontal ice flow into and out of the column during the measurement period, which may include short- as well as long-term dynamic changes. The sum of the last three terms determines the long-term mass balance.

In general, $\delta$ is a function of the time histories of $A(t)$ and $T(t)$ and the response time $\tau_{\mathrm{fc}}$ of the firn compaction process, which is on the order of a few years to decades. Our calculations of $\mathrm{d} C / \mathrm{d} t$ remove the effect of $T(t)$ for 10 years prior to and including the measurement period. However, because current knowledge of $A(t)$ is limited, the $\delta(\mathrm{d} l / \mathrm{d} t)_{\text {NStS }}$ term cannot be completely determined. Fortunately, several factors reduce the effect of variations of $A(t)$. First, short-term stochastic fluctuations in $A$ cause both positive and negative $\delta(\mathrm{d} / / \mathrm{d} t)_{\mathrm{NStS}}$ and therefore tend to average out in a 10 year period. However, such fluctuations appropriately increase our estimated error $\left(\sigma_{\mathrm{s}}\right)$ for $\mathrm{d} H / \mathrm{d} t$, 
Table 2. Mean values and errors in the estimate of ice-thickness change $(\mathrm{d} / \mathrm{d} t)$ and net mass balance $(\mathrm{d} / \mathrm{d} t$, $\mathrm{d} / \mathrm{M} / \mathrm{d} t)$ for grounded-ice $(\mathrm{g})$ and floating-ice (f) areas of drainage systems (DS) in Greenland, West Antarctica and East Antarctica, listing sea-level contribution (SLE) and the ratio of net mass balance to adjusted net accumulation at the surface $\left(A_{j j}\right)$ for each. All values are listed as computed to allow tracing of estimates in other columns (some second and third decimals are not significant); small differences are due to use of round-off values

\begin{tabular}{|c|c|c|c|c|c|c|c|c|c|c|}
\hline DS No.-name* & $\begin{array}{l}g \\
\text { or } \\
f\end{array}$ & Grid $^{\dagger}$ & Area & $\mathrm{d} l / \mathrm{d} t$ & $(\mathrm{~d} F / \mathrm{d} t)^{*}$ & $(\mathrm{~d} M / \mathrm{d} t)^{*}$ & SLE & $\mathrm{A}_{j}^{\S}$ & $A_{j j}{ }^{\top}$ & $\begin{array}{c}(\mathrm{d} F / \mathrm{d} t) \\
/ A_{j j}\end{array}$ \\
\hline
\end{tabular}

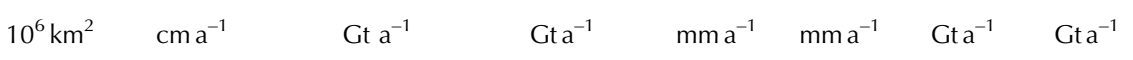

\begin{tabular}{|c|c|c|c|c|c|c|c|c|c|c|c|c|}
\hline \multicolumn{13}{|l|}{ Greenland } \\
\hline 1.1-NW:wKnRassL & $\mathrm{g}$ & 60 & 0.1608 & $+2.82 \pm 0.11$ & $+1.29 \pm 0.07$ & $+4.09 \pm 0.15$ & -0.004 & -0.011 & 16.12 & 16.12 & 0.080 & 0.253 \\
\hline 1.2-NW:eKnRassL & $\mathrm{g}$ & 37 & 0.0998 & $-2.83 \pm 0.29$ & $-1.82 \pm 0.12$ & $-2.54 \pm 0.26$ & +0.005 & +0.007 & 16.52 & 16.52 & -0.110 & -0.154 \\
\hline 2.1-NE:nKgF.VIIsL & $\mathrm{g}$ & 55 & 0.1472 & $+2.49 \pm 0.07$ & $+0.82 \pm 0.04$ & $+3.30 \pm 0.10$ & -0.002 & -0.009 & 7.56 & 7.56 & 0.109 & 0.436 \\
\hline 2.3-NE:sKgF.VIIsL & g & 18 & 0.0477 & $-0.43 \pm 0.09$ & $-1.50 \pm 0.02$ & $-0.19 \pm 0.04$ & +0.004 & +0.001 & -2.08 & -2.08 & 0.720 & 0.089 \\
\hline 3.1-CE:KgC.XsL & $\begin{array}{l}8 \\
\mathrm{~g}\end{array}$ & 60 & 0.1566 & $+7.07 \pm 1.26$ & $+4.37 \pm 0.79$ & $+9.97 \pm 1.78$ & -0.012 & -0.028 & 28.44 & 28.44 & 0.154 & 0.350 \\
\hline 3.2-CE:Blossev.Kyst & g & 45 & 0.1151 & $-14.34 \pm 0.82$ & $-10.54 \pm 0.38$ & $-14.86 \pm 0.85$ & +0.029 & +0.041 & 13.15 & 13.15 & -0.802 & -1.130 \\
\hline 4.1-SE:KgC.IXsL & g & 23 & 0.0582 & $+7.56 \pm 0.61$ & $+1.25 \pm 0.14$ & $+3.96 \pm 0.32$ & -0.003 & -0.011 & 0.57 & 0.57 & 2.185 & 6.931 \\
\hline 4.3-SE:KapFarvel & $\mathrm{g}$ & 14 & 0.0337 & $-27.33 \pm 0.74$ & $-6.56 \pm 0.10$ & $-8.29 \pm 0.22$ & +0.018 & +0.023 & -2.02 & -2.02 & 3.427 & 4.100 \\
\hline 5.1-SW:sDavisStr.S & g & 30 & 0.0734 & $-0.13 \pm 1.09$ & $-0.76 \pm 0.32$ & $-0.08 \pm 0.72$ & +0.002 & $+2 \times 10^{-4}$ & 14.12 & 14.12 & -0.054 & -0.006 \\
\hline 5.2-SW:cDavisStr.S & $\mathrm{g}$ & 58 & 0.1459 & $+2.52 \pm 0.15$ & $-1.20 \pm 0.09$ & $+3.31 \pm 0.19$ & +0.003 & -0.009 & -7.17 & -7.17 & 0.168 & -0.462 \\
\hline 5.3-SW:Jakobshavn & g & 34 & 0.0872 & $+7.06 \pm 0.19$ & $+1.86 \pm 0.07$ & $+5.54 \pm 015$ & -0.005 & -0.015 & 19.70 & 19.70 & 0.094 & 0.281 \\
\hline 5.4-SW:nDavisStr.S & $\mathrm{g}$ & 54 & 0.1400 & $+2.05 \pm 0.17$ & $-2.75 \pm 0.09$ & $+2.59 \pm 0.21$ & +0.008 & -0.007 & 13.36 & 13.36 & -0.206 & 0.194 \\
\hline 6.0-CentralWest & g & 98 & 0.2588 & $+4.50 \pm 0.20$ & $+1.98 \pm 0.20$ & $+10.47 \pm 0.46$ & -0.005 & -0.029 & 37.47 & 37.47 & 0.053 & 0.280 \\
\hline \multicolumn{13}{|l|}{ West Antarctica } \\
\hline 18-cRossIS & g & 73 & 0.1980 & $+4.02 \pm 0.17$ & $+3.18 \pm 0.14$ & $+7.17 \pm 0.31$ & -0.009 & -0.020 & 24.34 & 24.34 & 0.131 & 0.295 \\
\hline 19-eRossIS & $f$ & 33 & 0.0888 & $-10.84 \pm 1.78$ & $-3.72 \pm 0.61$ & $-8.38 \pm 1.37$ & & & 14.02 & 14.02 & -0.275 & -0.597 \\
\hline \multirow[t]{2}{*}{ 20-nMByrdL } & $\mathrm{g}$ & 76 & 0.2015 & $+1.24 \pm 0.95$ & $+1.00 \pm 0.76$ & $+2.25 \pm 1.71$ & -0.003 & -0.006 & 57.56 & 50.54 & 0.020 & 0.045 \\
\hline & f & 22 & 0.0582 & $-61.32 \pm 4.96$ & $-13.79 \pm 1.12$ & $-31.05 \pm 2.51$ & & & 20.51 & 20.51 & -0.696 & -1.514 \\
\hline \multirow[t]{2}{*}{ 21-Smi./Thw.G } & g & 83 & 0.2213 & $-22.88 \pm 0.71$ & $-20.23 \pm 0.63$ & $-45.57 \pm 1.42$ & +0.056 & +.126 & 72.92 & 69.22 & -0.293 & -0.658 \\
\hline & $\mathrm{f}$ & 3 & 0.0079 & $-203.8 \pm 57.1$ & $-6.22 \pm 1.74$ & $-14.01 \pm 3.93$ & & & 6.19 & 6.19 & -1.040 & -2.263 \\
\hline \multirow[t]{2}{*}{ 22-PinelslandG } & $\mathrm{g}$ & 74 & 0.1966 & $-9.71 \pm 0.78$ & $-7.63 \pm 0.61$ & $-17.19 \pm 1.38$ & +0.021 & +0.047 & 83.00 & 80.26 & -0.095 & -0.214 \\
\hline & f & 2 & 0.0053 & $-216 . \pm 193$ & $-4.44 \pm 3.96$ & $-10.0 \pm 8.92$ & & & 3.84 & 3.84 & -1.198 & -2.605 \\
\hline \multirow[t]{2}{*}{ 23-nEllsworthL } & $\mathrm{g}$ & 34 & 0.0892 & $-3.32 \pm 1.31$ & $-1.18 \pm 0.47$ & $-2.67 \pm 1.05$ & +0.003 & +0.007 & 73.55 & 63.58 & -0.019 & -0.042 \\
\hline & $f$ & 15 & 0.0392 & $-8.76 \pm 4.98$ & $-1.33 \pm 0.75$ & $-2.99 \pm 1.70$ & & & 35.09 & 35.09 & -0.039 & -0.085 \\
\hline \multirow[t]{2}{*}{ 24-wPalmerL } & $\mathrm{g}$ & 66 & 0.1716 & $+2.97 \pm 1.92$ & $+2.03 \pm 1.32$ & $+4.58 \pm 2.97$ & -0.006 & -0.013 & 107.38 & 93.21 & 0.022 & 0.049 \\
\hline & $f$ & 22 & 0.0572 & $-55.85 \pm 4.01$ & $-12.34 \pm 0.89$ & $-27.80 \pm 2.00$ & & & 50.34 & 50.34 & -0.254 & -0.552 \\
\hline 1-wFilch.-Ron.IS & g & 177 & 0.4743 & $+1.80 \pm 0.33$ & $+3.40 \pm 0.63$ & $+7.67 \pm 1.42$ & -0.009 & -0.021 & 113.59 & 106.58 & 0.032 & 0.072 \\
\hline & $f$ & 108 & 0.2890 & $+21.76 \pm 1.20$ & $+24.29 \pm 1.34$ & $+54.71 \pm 3.01$ & & & & & 0.434 & 0.943 \\
\hline 26-LarsenIS & $f$ & 26 & 0.0656 & $-17.92 \pm 4.73$ & $-4.54 \pm 1.20$ & $-10.23 \pm 2.70$ & & & 58.55 & 58.55 & -0.080 & -0.175 \\
\hline East Antarcti & & & & & & & & & & & & \\
\hline 2-cFilch.-Ron.IS & $\mathrm{g}$ & 328 & 0.8933 & $-0.12 \pm 0.07$ & $-0.42 \pm 0.24$ & $-0.94 \pm 0.54$ & +0.001 & +0.003 & 77.42 & 74.85 & -0.006 & -0.013 \\
\hline & $f$ & 42 & 0.1132 & $+12.60 \pm 1.31$ & $+5.51 \pm 0.57$ & $+12.41 \pm 1.29$ & & & 18.88 & 18.88 & 0.302 & 0.657 \\
\hline 4-CoatsL & g & 97 & 0.2563 & $+2.90 \pm 0.23$ & $+2.98 \pm 0.24$ & $+6.70 \pm 0.53$ & -0.008 & -0.019 & 52.01 & 45.80 & 0.065 & 0.146 \\
\hline & $f$ & 27 & 0.0709 & $+31.46 \pm 4.29$ & $+8.62 \pm 1.18$ & $+19.41 \pm 2.65$ & & & 27.52 & 27.52 & 0.324 & 0.705 \\
\hline 5-wDMaudL & g & 79 & 0.2065 & $+7.42 \pm 1.01$ & $+6.12 \pm 0.83$ & $+13.78 \pm 1.87$ & -0.017 & -0.038 & 32.23 & 28.23 & 0.217 & 0.488 \\
\hline & f & 18 & & $+59.22 \pm 8.33$ & $+10.64 \pm 1.50$ & $+23.96 \pm 3.37$ & & & 12.54 & 12.54 & 0.878 & 1.911 \\
\hline 6-eDMaudL & $\mathrm{g}$ & 231 & 0.6038 & $-0.32 \pm 0.21$ & $-0.77 \pm 0.52$ & $-1.73 \pm 1.16$ & +0.002 & +0.005 & 64.02 & 56.80 & -0.014 & -0.030 \\
\hline & $f$ & 30 & 0.0772 & $+24.97 \pm 2.10$ & $+7.45 \pm 0.63$ & $+16.77 \pm 1.41$ & & & 19.51 & 19.51 & 0.395 & 0.860 \\
\hline 7-EnderbyL & $\mathrm{g}$ & 179 & 0.4624 & $-1.19 \pm 1.20$ & $-2.20 \pm 2.22$ & $-4.95 \pm 5.00$ & +0.006 & +0.014 & 61.17 & 53.91 & -0.041 & -0.092 \\
\hline & f & 1 & 0.0026 & $+5.69 \pm 17.65$ & $+0.06 \pm 0.18$ & $+0.13 \pm 0.40$ & & & 0.89 & 0.89 & 0.067 & 0.145 \\
\hline 8-KempL & g & 61 & 0.1554 & $-14.51 \pm 2.73$ & $-9.01 \pm 1.69$ & $-20.29 \pm 3.81$ & +0.025 & +0.056 & 28.49 & 23.40 & -0.385 & -0.867 \\
\hline & f & 1 & 0.0025 & $+11.20 \pm 17.11$ & $+0.11 \pm 0.17$ & $+0.24 \pm 0.37$ & & & 0.89 & 0.89 & 0.126 & 0.274 \\
\hline 9-wAmeryIS & g & 60 & 0.1550 & $+4.24 \pm 0.73$ & $+2.63 \pm 0.45$ & $+5.92 \pm 1.02$ & -0.007 & -0.016 & 14.69 & 13.83 & 0.190 & 0.428 \\
\hline & f & 6 & 0.0154 & $+34.78 \pm 5.30$ & $+2.07 \pm 0.32$ & $+4.66 \pm 0.71$ & & & 3.64 & 3.64 & 0.589 & 1.280 \\
\hline 10-cAmeryIS & $\mathrm{g}$ & 351 & 0.9336 & $-0.68 \pm 0.07$ & $-2.55 \pm 0.28$ & $-5.75 \pm 0.63$ & +0.007 & +0.016 & 47.74 & 47.74 & -0.054 & -0.120 \\
\hline & $f$ & 8 & 0.0206 & $+55.11 \pm 5.36$ & $+4.39 \pm 0.43$ & $+9.88 \pm 0.96$ & & & 4.04 & 4.04 & 1.124 & 2.445 \\
\hline 11-eAmeryIS & $\mathrm{g}$ & 93 & 0.2435 & $-0.08 \pm 0.24$ & $-0.08 \pm 0.24$ & $-0.17 \pm 0.53$ & $+2 \times 10^{-4}$ & $+5 \times 10^{-4}$ & 18.36 & 18.04 & -0.004 & -0.009 \\
\hline & f & 5 & 0.0129 & $+42.96 \pm 4.27$ & $+2.14 \pm 0.21$ & $+4.82 \pm 0.48$ & & & 2.89 & 2.89 & 0.767 & 1.668 \\
\hline 12-DavisSeaS & $\mathrm{g}$ & 279 & 0.7163 & $+1.68 \pm 0.81$ & $+4.82 \pm 2.33$ & $+10.86 \pm 5.24$ & -0.013 & -0.030 & 153.04 & 140.26 & 0.034 & 0.077 \\
\hline & f & 21 & & $+91.50 \pm 10.71$ & $+18.63 \pm 2.18$ & $+41.95 \pm 4.91$ & & & 26.86 & 26.86 & 0.718 & 1.562 \\
\hline 13-WilkesL & g & 430 & 1.1114 & $-1.38 \pm 0.20$ & $-6.15 \pm 0.90$ & $-13.85 \pm 2.02$ & +0.017 & +0.038 & 226.63 & 206.82 & -0.030 & -0.067 \\
\hline & $f$ & 6 & 0.0151 & $+4.75 \pm 38.31$ & $+0.28 \pm 2.24$ & $+0.62 \pm 5.03$ & & & 8.20 & 8.20 & 0.035 & 0.076 \\
\hline 14-TerreAdélie & g & 268 & 0.6910 & $-0.02 \pm 0.24$ & $-0.07 \pm 0.67$ & $-0.15 \pm 1.51$ & $+2 \times 10^{-4}$ & $+4 \times 10^{-4}$ & 147.57 & 135.87 & -0.001 & -0.001 \\
\hline & $f$ & 6 & 0.0152 & $-90.32 \pm 20.45$ & $-5.30 \pm 1.20$ & $-11.94 \pm 2.70$ & & & 0.79 & 0.79 & -6.951 & -15.119 \\
\hline 15-nVictoriaL & g & 54 & 0.1405 & $-3.53 \pm 4.19$ & $-1.98 \pm 2.36$ & $-4.46 \pm 5.30$ & +0.005 & +0.012 & 30.52 & 27.67 & -0.072 & -0.161 \\
\hline & f & 2 & 0.0052 & $-47.96 \pm 21.05$ & $-0.96 \pm 0.42$ & $-2.17 \pm 0.95$ & & & 1.60 & 1.60 & -0.623 & -1.356 \\
\hline 16-sVictoriaL & $\mathrm{g}$ & 99 & 0.2619 & $+2.25 \pm 0.34$ & $+2.36 \pm 0.35$ & $+5.30 \pm 0.79$ & -0.007 & -0.015 & 20.99 & 20.63 & 0.114 & 0.257 \\
\hline & f & 1 & 0.0026 & $-8.85 \pm 12.87$ & $-0.09 \pm 0.13$ & $-0.20 \pm 0.29$ & & & 0.13 & 0.13 & -0.708 & -1.539 \\
\hline 17-wRossIS & $g$ & 685 & 1.8481 & $+0.89 \pm 0.06$ & $+6.56 \pm 0.42$ & $+14.77 \pm 0.95$ & -0.018 & -0.041 & 114.85 & 114.85 & 0.057 & 0.129 \\
\hline & $\mathrm{f}$ & 82 & 0.2212 & $+9.10 \pm 0.81$ & $+7.77 \pm 0.69$ & $+17.51 \pm 1.56$ & & & 33.72 & 33.72 & 0.239 & 0.519 \\
\hline
\end{tabular}

Footnotes on facing page. 

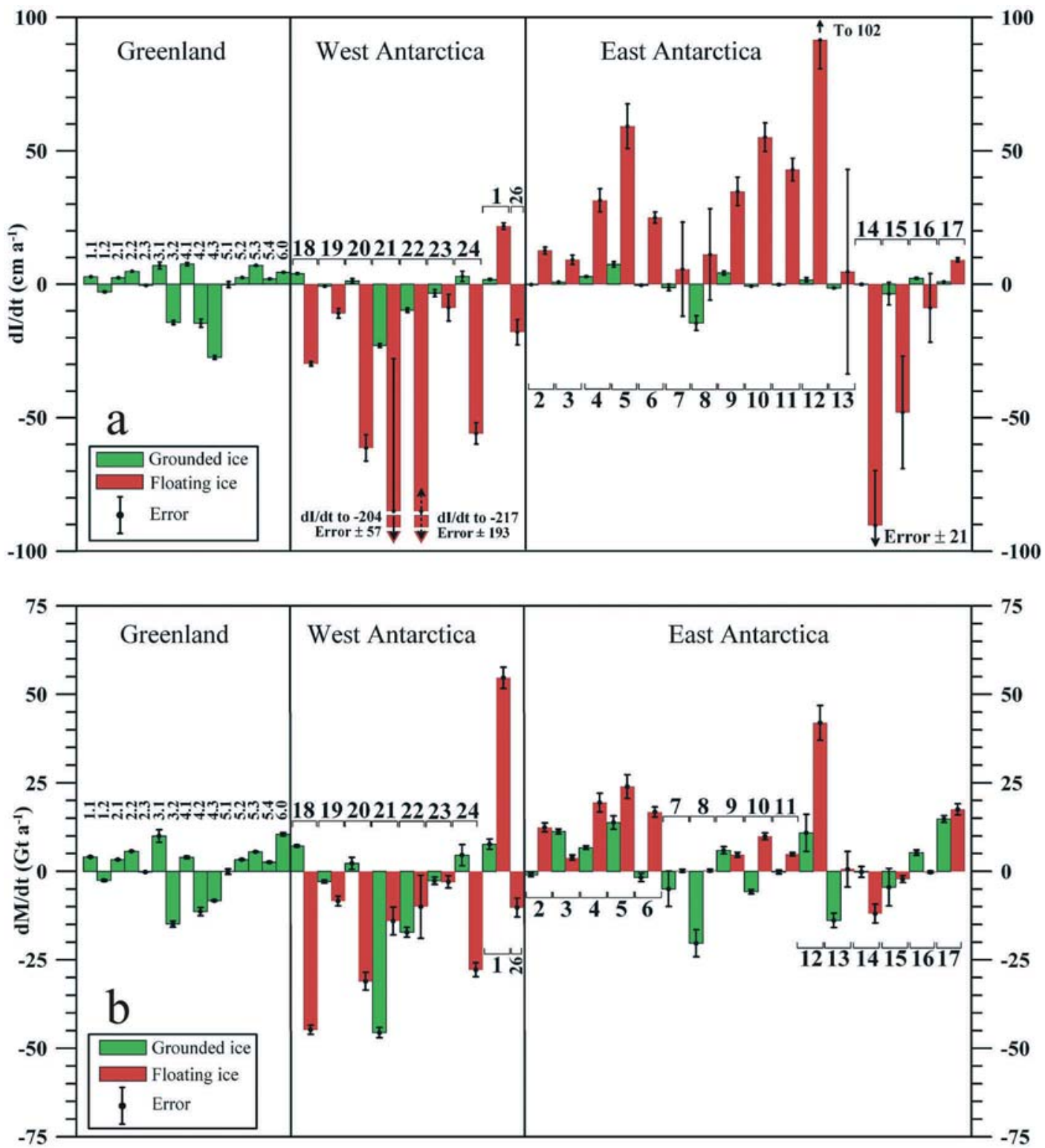

Fig. 4. Distribution of mean $\mathrm{d} / / \mathrm{d} t(\mathrm{a})$ and $\mathrm{d} M / \mathrm{d} t(\mathrm{~b})$ for drainage systems of Greenland, West Antarctica and East Antarctica (EA includes data for DS1g\&f, and DS26f).

an example of which is discussed below for an apparently non-linear $H(t)$. Second, in integrals of $\mathrm{d} M / \mathrm{d} t$ over large regions, some of the $\delta(\mathrm{d} l / \mathrm{d} t)_{\mathrm{NStS}}$ are likely to be positive and some negative, thereby also reducing their net effect. Therefore, we use the approximation

$$
\frac{\mathrm{d} M}{\mathrm{~d} t}=\rho_{\mathrm{a}} \frac{\mathrm{d} I}{\mathrm{~d} t} \mathrm{Ar},
$$

where $\rho_{\mathrm{a}}$ is the average density of the firn/ice column, i.e. 0.90 on grounded ice and 0.87 on floating ice, and $\mathrm{d} l / \mathrm{d} t$ is the observed thickness change. We show $\mathrm{d} M / \mathrm{d} t$ for Greenland and Antarctic sub-regions and drainage systems in
Tables 1 and 2 and Figure $4 \mathrm{~b}$ and discuss the results in the next section.

Our approximation is equivalent to assuming the $\mathrm{d} / / \mathrm{d} t$ are distributed throughout the firn/ice column, and that NStS firn compaction terms are on average small compared to the longer-term balance terms. As improved information on $A(t)$ is acquired (e.g. Box and others, in press; Monaghan and others, in press) the effect on densification can be calculated and $\delta(\mathrm{d} l / \mathrm{d} t)_{\mathrm{NStS}}$ estimated. Meanwhile, we note that changes in $A(t)$ tend to be positively correlated with $T(t)$, with data and models showing correlations ranging from about 5 to $20 \%$ per kelvin (e.g. Zwally, 1989, n.26; Kapsner and

Table 2 Footnotes.

*Prefixes: n, northern; s, southern; w, western; c, central; e, eastern. Suffixes: IS, Ice Shelf; L, Land; S, sector; G, Glacier.

TThe whole area of DS25 and 27, and the area of grounded ice in DS26, are excluded from the study (see Table 1 footnote *).

tThe net mass-balance computations $(\mathrm{d} / \mathrm{d} t, \mathrm{~d} M / \mathrm{d} t)$ use mean $\mathrm{d} / / \mathrm{d} t$ adjusted for area, factored as described in Table 1 footnote ${ }^{\S}$.

${ }^{\S}$ Surface balance data for Greenland and Antarctica from Zwally and Giovinetto (2000) and Giovinetto and Zwally (2000) respectively; data for DS26(f) from Vaughan and others (1999) and D.G. Vaughan (personal communication, 1999).

'Surface balance after deflation and ablation corrections have been applied (Antarctica, grounded ice only; modified from Giovinetto and Zwally, 2000). 


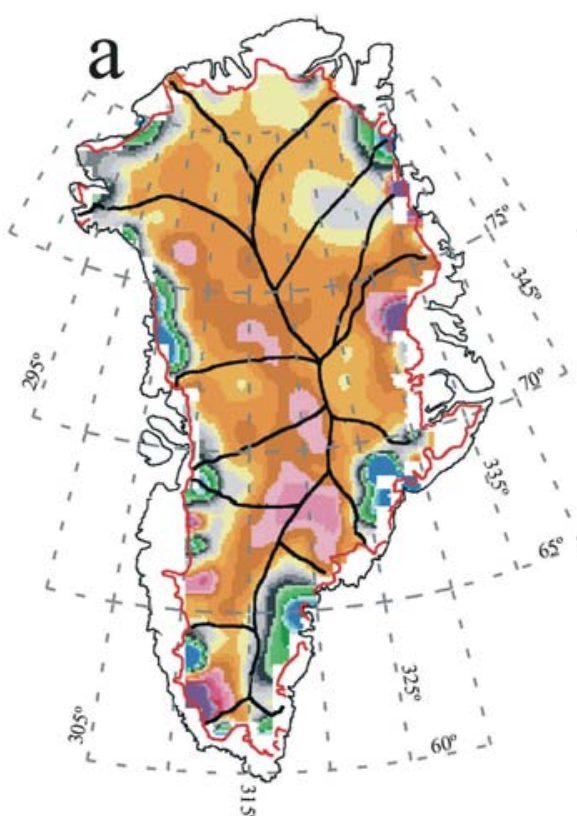

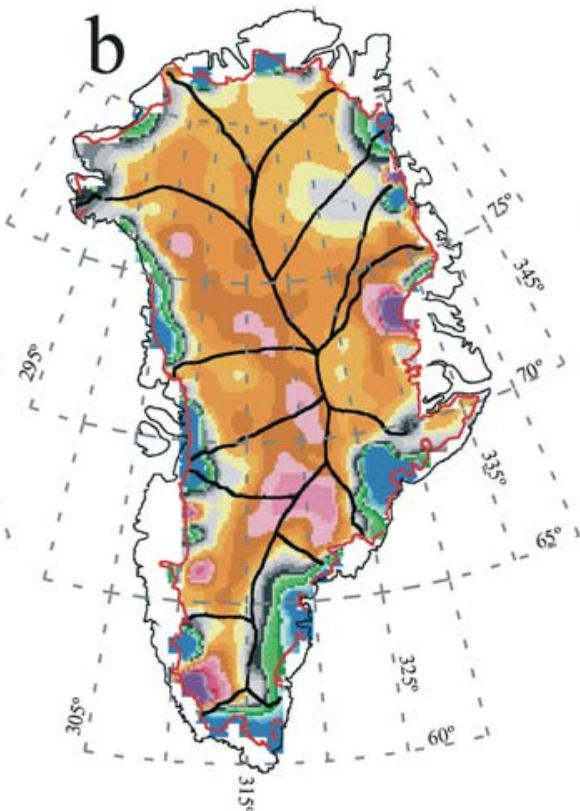
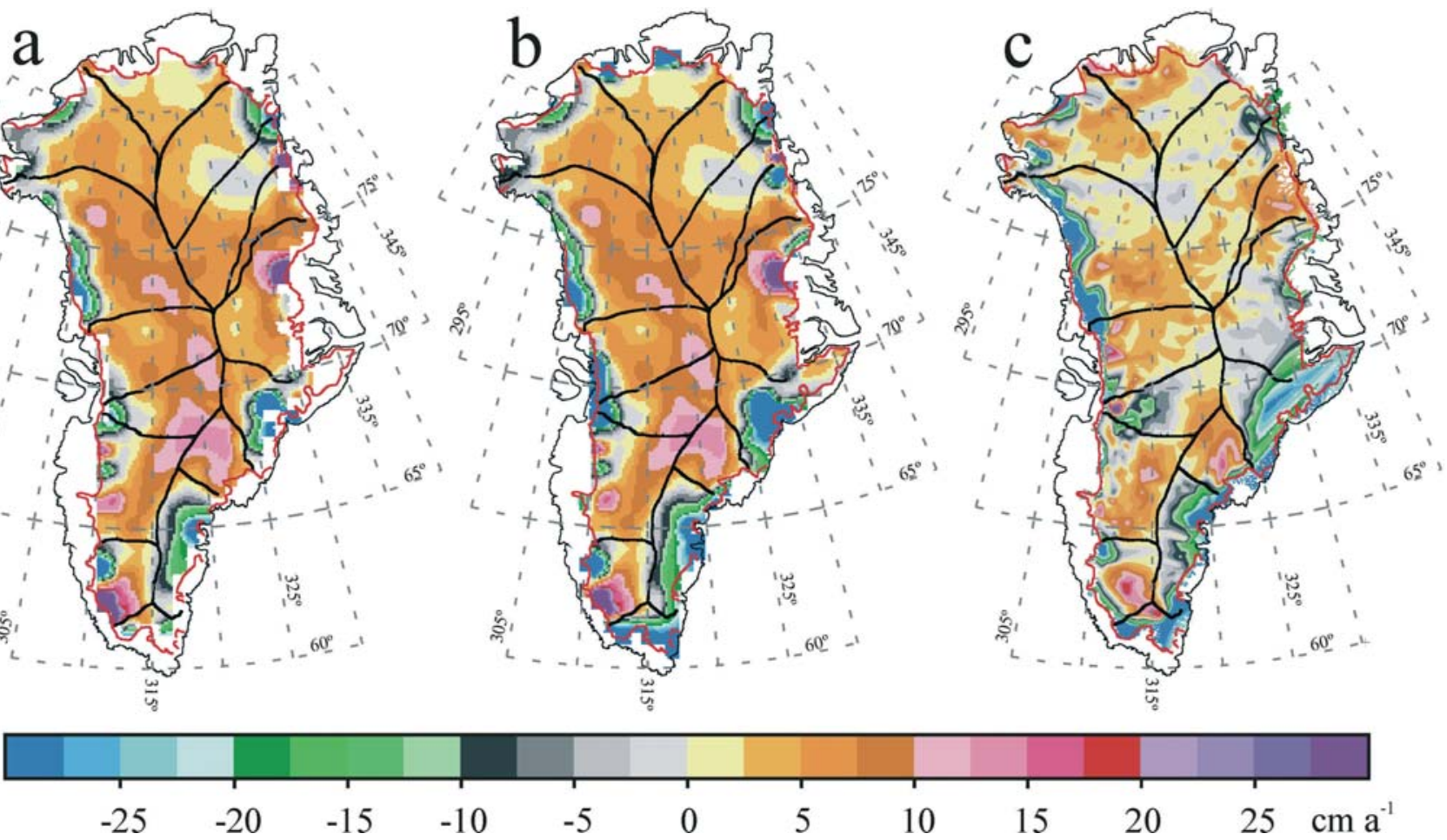

Fig. 5. Comparison of $\mathrm{d} H / \mathrm{d} t$ distribution for Greenland: (a) ERS only; (b) same as in Figure 1b; and (c) produced by interpolation and extrapolation of airborne laser altimeter and ATM surveys data collected in 1993-99 (Krabill and others, 2000).

others, 1995). Therefore, where $A(t)$ is correlated with $T(t)$, our approximation will estimate greater mass gain or less mass loss than is actually occurring in regions that are warming, and less mass gain or greater mass loss than is actually occurring in regions that are cooling. The magnitude of this effect depends on the timescale of the variations in $A(t)$. As noted, sub-decadal variations tend to average out in a 10 year observation. Decadal trends during only the measurement period would have the most impact, while decadal trends that are part of a longer-term trend would have small impact because the non-steady-state densification term would be small.

Alternatively, choosing a smaller value of $\rho_{\text {a }}$ would further reduce our estimates of overall mass imbalance, which are shown to be small. To increase our estimates of mass imbalance, or to change their sign, would require selective application of $\delta$ values regionally and/or assumptions regarding the relative magnitude of the dynamic vs surface-balance terms in Equation (3). Previously, a commonly used $\rho_{\mathrm{a}}$, implicitly or explicitly, was the 0.92 density of ice (e.g. Krabill and others, 2000). Zwally (1989) used 0.5 and 0.92 to give a range of mass estimates. Davis and others (2005) used $\rho_{\mathrm{a}}=0.35$ to estimate $\mathrm{d} M / \mathrm{d} t$ based on a positive $\mathrm{d} H / \mathrm{d} t$ in EA. However, the surface density is close to 0.3 in most locations, and 0.35 is the typical density of the top annual layer or two. Therefore, using 0.35 is equivalent to assuming that a positive $\mathrm{d} H / \mathrm{d} t$ is continuously caused solely by the addition of new firn, with little subsequent compaction from year to year, and that the long-term mass-balance terms (accumulation plus dynamic) in Equation (3) are zero. In that case, Equation (3) would be

$$
\frac{\mathrm{d} F}{\mathrm{~d} t}=\rho_{\text {ice }}\left[\delta\left(\frac{\mathrm{d} /}{\mathrm{d} t}\right)_{\mathrm{NStS}}+0\right] \mathrm{Ar},
$$

where all thickness changes are assumed to be caused by short-term changes in accumulation and $F$ is the change in mass of the firn. To illustrate the effect of this assumption on estimates of the overall mass-balance values, in Tables 1 and 2 we also list $\mathrm{d} F / \mathrm{d} t$ values using $\delta=0.44$ or $\rho_{\mathrm{a}}=0.4$, which is a typical mean density for the top strata corresponding to 10 years of accumulation as shown by widespread sampling of the ice sheets (e.g. Benson, 1962; Kojima, 1964). The $\mathrm{d} F / \mathrm{d} t$ calculations include the $\mathrm{d} C / \mathrm{d} t$ correction for temperature effects on firn compaction.

Finally, we note that our $\mathrm{d} M / \mathrm{d} t$ estimates for the ice shelves include mass changes caused by thickening or thinning, which may be affected by changes in the rate of discharge of grounded ice into the shelves. However, the estimates do not take into account mass changes resulting from possible systematic changes in the ice-shelf fronts due to episodic calving events (e.g. Zwally and others, 2002b) or ice-shelf disintegration (e.g. Skvarca and others, 1999).

\section{DISCUSSION OF REGIONAL CHANGES IN ELEVATION, THICKNESS AND MASS}

In Greenland, most $\mathrm{d} H / \mathrm{d} t$ values on the inland ice sheet above $2000 \mathrm{~m}$ are increasing in the range $0-15 \mathrm{~cm} \mathrm{a}^{-1}$ (Fig. 1b), with an average of $4.77 \pm 0.14 \mathrm{~cm} \mathrm{a}^{-1}$ (Table 1). For example, $\mathrm{d} H / \mathrm{d} t$ for four inland locations at central west (CW: $13.5 \pm 1.6 \mathrm{~cm} \mathrm{a}^{-1}$ ), southwest (SW: $12.0 \pm 1.7 \mathrm{~cm} \mathrm{a}^{-1}$ ), central east (CE: $8.4 \pm 0.5 \mathrm{~cm} \mathrm{a}^{-1}$ ) and north central (NC: $5.2 \pm 0.5 \mathrm{~cm} \mathrm{a}^{-1}$ ) illustrate the mostly linear trends of increasing elevation. However, the region near the summit (NS: $3.0 \pm 0.8 \mathrm{~cm} \mathrm{a}^{-1}$ ), which had an accumulation low around 1994/95 (McConnell and others, 2001), had a decreasing $\mathrm{d} H / \mathrm{d} t$ for the first 3 years followed by an increase.

At elevations above $2000 \mathrm{~m}$, our $\mathrm{d} H / \mathrm{d} t$ appear very similar in some regions to those from ATM surveys made 
Table 3. Comparison of $\mathrm{d} H / \mathrm{d} t$ for Greenland from this study with ATM results of Krabill and others (2000). Values listed as computed (some second decimals are not significant)

\begin{tabular}{|c|c|c|c|c|c|}
\hline \multicolumn{3}{|l|}{ Surface elevation zone } & \multirow{3}{*}{$\begin{array}{l}\text { This study (all data) } \\
\qquad \begin{array}{l}\mathrm{d} H / \mathrm{d} t^{*} \\
\mathrm{~cm} \mathrm{a}^{-1}\end{array}\end{array}$} & \multirow{3}{*}{$\begin{array}{l}\text { Other study } \\
\qquad \begin{array}{c}\mathrm{d} H / \mathrm{d} t^{\dagger} \\
\mathrm{cm} \mathrm{a}^{-1}\end{array}\end{array}$} & \multirow{3}{*}{$\begin{array}{c}\text { Diff. in } \mathrm{d} H / \mathrm{d} t \\
\mathrm{~cm} \mathrm{a}^{-1}\end{array}$} \\
\hline & $N$ & Area & & & \\
\hline km & & $10^{6} \mathrm{~km}^{2}$ & & & \\
\hline Overall & 670 & 1.7411 & $-0.75 \pm 0.35$ & -2.04 & +1.29 \\
\hline $2.7-3.3$ & 144 & 0.3740 & $+6.26 \pm 0.14$ & +0.93 & +5.33 \\
\hline $2.2-2.7$ & 201 & 0.5203 & $+3.99 \pm 0.25$ & +0.44 & +3.55 \\
\hline $1.7-2.2$ & 135 & 0.3526 & $+1.92 \pm 0.67$ & -1.48 & +3.40 \\
\hline $1.2-1.7$ & 105 & 0.2728 & $-4.09 \pm 1.36$ & -6.58 & +2.49 \\
\hline $0.7-1.2$ & 57 & 0.1486 & $-17.02 \pm 2.12$ & -11.33 & -5.69 \\
\hline $0.2-0.7$ & 22 & 0.0576 & $-33.85 \pm 3.66$ & -14.15 & -19.70 \\
\hline $0.0-0.2$ & 6 & 0.0152 & $-53.22 \pm 8.71$ & -15.01 & -38.21 \\
\hline$>2.0$ & 401 & 1.0404 & $+4.77 \pm 0.14$ & +0.45 & +4.32 \\
\hline$<2.0$ & 269 & 0.7007 & $-8.95 \pm 0.85$ & -6.51 & -2.44 \\
\hline$>1.2$ & 585 & 1.5197 & $+2.62 \pm 0.30$ & -1.00 & -1.62 \\
\hline$<1.2$ & 85 & 0.2214 & $-23.88 \pm 1.82$ & -12.16 & -11.72 \\
\hline
\end{tabular}

*Area-weighted mean values.

${ }^{\dagger}$ Computed from data from W. Krabill (personal communication, 2000).

between 1993 and 1998 in the south and 1994 and 1999 in the north (Krabill and others, 2000), but are more uniformly positive over the ice sheet (Fig. 5). The principal region of elevation decreases above $2000 \mathrm{~m}$ in both datasets is in the southeast (DS4.1 and 4.2) where, for example, $\mathrm{d} H / \mathrm{d} t=$ $-12.7 \pm 1.7 \mathrm{~cm} \mathrm{a}^{-1}$ at point SE at $2173 \mathrm{~m}$ (Fig. 3a). Our $\mathrm{d} H / \mathrm{d} t$ results are compared with our calculation of the ATM data by elevation intervals in Table 3. Above $2000 \mathrm{~m}$ our average $\mathrm{d} H / \mathrm{d} t$ of $+4.77 \mathrm{~cm} \mathrm{a}^{-1}$ is larger than the $+0.5 \pm 0.5 \mathrm{~cm} \mathrm{a}^{-1}$ for the ATM data (Krabill and others, 2000; Table 3), or the $+1.0 \pm 0.5 \mathrm{~cm} \mathrm{a}^{-1}$ as given by Thomas and others (2001) and revised to $+1.4 \pm 0.5 \mathrm{~cm} \mathrm{a}^{-1}$ (personal communication from R. Thomas, 2005). These differences may be due to the limited spatial and temporal sampling of the ATM data and to sensitivity to seasonal changes in elevation, because the ATM flights made around May and June occur at the time of maximum change in the rate of firn compaction (Zwally and Li, 2002).

At Greenland elevations below $2000 \mathrm{~m}$, the pattern of decreases in most areas is in good agreement with the ATMbased values (Fig. 5). Some of the differences near the margins are probably due to the extrapolation/interpolation of ATM values to the ice margins using temperatures at coastal weather stations (Krabill and others, 2000), compared to our direct extrapolation/interpolation of ERS and ATM data. Our average $\mathrm{d} H / \mathrm{d} t$ below $2000 \mathrm{~m}$ is $-8.95 \pm$ $0.85 \mathrm{~cm} \mathrm{a}^{-1}$, which indicates more thinning than our calculation of $\mathrm{d} H / \mathrm{d} t=-6.5 \mathrm{~cm} \mathrm{a}^{-1}$ for the ATM data (Table 3). Below $1200 \mathrm{~m}$, which is the approximate equilibrium-line altitude (ELA), the respective $\mathrm{d} H / \mathrm{d} t$ are $-23.88 \pm 1.82 \mathrm{~cm} \mathrm{a}^{-1}$ for our results and $-12.2 \mathrm{~cm} \mathrm{a}^{-1}$ for the ATM.

In general, our $\mathrm{d} H / \mathrm{d} t$ show more thickening at higher elevations and more thinning at lower elevations than the ATM data. Krabill and others (2000) reported a net ice loss of $51 \mathrm{~km}^{3} \mathrm{a}^{-1}$ (or $45.9 \mathrm{Gta}^{-1}$ using $\rho=0.9$ ), but were 'unable to assign errors' to their estimate. They used a value of $\mathrm{d} B / \mathrm{d} t=0.5 \mathrm{~cm} \mathrm{a}^{-1}$ in the north and $0.4 \mathrm{~cm} \mathrm{a}^{-1}$ in the south compared to our overall average of $0.06 \mathrm{~cm} \mathrm{a}^{-1}$, which would reduce their mass loss by $6.2 \mathrm{Gta}^{-1}$. Applying our firn compaction correction reduces their loss by another $23.4 \mathrm{Gta}^{-1}$, and applying their revised $\mathrm{d} H / \mathrm{d} t$ of
$+1.4 \pm 0.5 \mathrm{~cm} \mathrm{a}^{-1}$ (from $+0.5 \pm 0.5 \mathrm{~cm} \mathrm{a}^{-1}$ ) above $2000 \mathrm{~m}$ reduces it by another $8.4 \mathrm{Gta}^{-1}$ to a net mass loss of only $8 \mathrm{Gta}^{-1}$, which is very close to balance.

In contrast, our $\mathrm{d} H / \mathrm{d} t$ agree within $\pm 1 \mathrm{~cm} \mathrm{a}^{-1}$ with those reported by Johannessen and others (2005) for elevations above $2500 \mathrm{~m}$ (Table 4). At lower elevations, their $\mathrm{d} H / \mathrm{d} t$ are increasingly more positive than both our ERS-only results and our ERS + ATM + optimal interpolation results. Residual differences at the higher elevations may be due to their not applying a backscatter correction that they estimate to be approximately $-0.8 \mathrm{~cm} \mathrm{a}^{-1}$. However, our less positive $\mathrm{d} H / \mathrm{d} t$ between 1500 and $2500 \mathrm{~m}$ and our more negative $\mathrm{d} H / \mathrm{d} t$ below $1500 \mathrm{~m}$ are probably due to the greater coverage of our values derived from ERS only (e.g. $92 \%$ vs $71 \%$ between 1500 and $2000 \mathrm{~m}$ ) and our inclusion of values from ATM and optimal interpolation.

Our $\mathrm{d} H / \mathrm{d} t$ at four sample locations (JI, HG, NM and NI) with elevations of 472-1365 m have elevation decreases of $7.4-42.2 \mathrm{~cm} \mathrm{a}^{-1}$. The $H(t)$ for the two locations below the ELA, Humboldt Glacier (HG) and 'Northeast Greenland Ice Stream' (NI), show clear seasonal cycles of several meters amplitude, with minima on 24 and 6 August near the end of the summer ablation season. These $H(t)$ clearly illustrate the capability of our analysis techniques to derive realistic $H(t)$ in some of the low-elevation margins of the ice sheets. The two locations just above the ELA, North Margin (NM) and Jakobshavn Isbræ (JI), also have seasonal cycle minima (on 16 September and 15 August) due to the summer melting and firn compaction. The distributions of $\mathrm{d} / \mathrm{d} t$ values above and below the ELA and above and below $2000 \mathrm{~m}$ effectively show increases in the higher elevations and decreases in the lower elevations, with average values shown in Figure 6.

Nine drainage systems distributed over the NW and NE (DS1.1, 2.1, 2.2), CE (DS3.1), SE (DS4.1), and the SW and CW (DS5.2-5.4, 6.0), covering $74 \%$ of the area of the ice sheet, have $\mathrm{d} M / \mathrm{d} t$ increases that range between $+2.6 \pm 0.2$ and $+10.5 \pm 0.5 \mathrm{Gta}^{-1}$. Five systems distributed over the NW (DS1.2), NE (DS2.3), CE (DS3.2) and SE (DS4.2, 4.3), covering $22 \%$ of the ice sheet, show $\mathrm{d} M / \mathrm{d} t$ decreases between $0.19 \pm 0.04$ and $14.9 \pm 0.9 \mathrm{Gta}^{-1}$. The estimated 
Table 4. Comparison of $\mathrm{d} H / \mathrm{d} t$ for Greenland from this study for all data and for ERS data only with the ERS results of Johannessen and others (2005). Values listed as computed (some second decimals are not significant)

\begin{tabular}{|c|c|c|c|c|c|c|c|c|c|c|c|c|}
\hline \multirow{3}{*}{$\begin{array}{l}\begin{array}{l}\text { Surface } \\
\text { elevation } \\
\text { zone }\end{array} \\
\text { km }\end{array}$} & \multicolumn{3}{|c|}{ This study (all data) } & \multicolumn{4}{|c|}{ This study (ERS only) } & \multicolumn{3}{|c|}{$\begin{array}{l}\text { Other study } \\
\text { (ERS only) }\end{array}$} & \multicolumn{2}{|c|}{ Diff. in $\mathrm{d} H / \mathrm{d} t$} \\
\hline & $\mathrm{d} H / \mathrm{d} t^{*}$ & Area & $N$ & $\mathrm{~d} H / \mathrm{d} t^{*}$ & Are & & $N$ & $\mathrm{~d} H / \mathrm{d} t$ & Are & & (2) minus (9) & (5) minus (9) \\
\hline & $\mathrm{cm} \mathrm{a}^{-1}$ & $10^{6} \mathrm{~km}^{2}$ & & $\mathrm{~cm} \mathrm{a}^{-1}$ & $10^{6} \mathrm{~km}^{2}$ & $\%$ & & $\mathrm{~cm} \mathrm{a}^{-1}$ & $10^{6} \mathrm{~km}^{2}$ & $\%^{\dagger}$ & $\mathrm{cm} \mathrm{a}^{-1}$ & $\mathrm{~cm} \mathrm{a}^{-1}$ \\
\hline (1) & (2) & (3) & (4) & (5) & (6) & (7) & (8) & (9) & (10) & (11) & (12) & (13) \\
\hline Overall & $-0.75 \pm 0.35$ & 1.7411 & 670 & $+2.70 \pm 0.28$ & 1.5678 & 90 & 602 & $+5.4 \pm 0.2$ & 1.3807 & 79 & $-6.15 \pm 0.40$ & $-2.70 \pm 0.34$ \\
\hline$>3.0$ & $+6.34 \pm 0.20$ & 0.1067 & 41 & $+6.34 \pm 0.20$ & 0.1067 & 100 & 41 & $+5.5 \pm 0.3$ & 0.1403 & 131 & $+0.84 \pm 0.36$ & $+0.84=$ \\
\hline $2.5-3.0$ & $+5.89 \pm 0.19$ & 0.4773 & 184 & $+5.94 \pm 0.13$ & 0.4747 & 99 & 183 & $+6.4 \pm 0.3$ & 0.4583 & 96 & $-0.51 \pm 0.36$ & $-0.46 \pm 0.36$ \\
\hline $2.0-2.5$ & $+3.32 \pm 0.24$ & 0.4563 & 176 & $+3.35 \pm 0.23$ & 0.4513 & 99 & 174 & $+7.0 \pm 0.4$ & 0.3989 & 87 & $-3.68 \pm 0.47$ & $-3.65 \pm 0.46$ \\
\hline $1.5-2.0$ & $+0.36 \pm 0.96$ & 0.3210 & 123 & $+1.87 \pm 0.84$ & 0.2960 & 92 & 113 & $+5.6 \pm 0.5$ & 0.2282 & 71 & $-5.24 \pm 1.08$ & $-3.73 \pm 0.98$ \\
\hline$>1.5$ & $-16.81 \pm 1.34$ & 0.3797 & 146 & $-5.56 \pm 1.42$ & 0.2390 & 63 & 91 & $-2.0 \pm 0.9$ & 0.1551 & 41 & $-14.81 \pm 1.61$ & $-3.56 \pm 1.68$ \\
\hline
\end{tabular}

*Area-weighted mean values.

${ }^{\dagger}$ Area $\%$ is relative to our area for each zone; value greater than $100 \%$ above $3 \mathrm{~km}$ is unexplained.

change in the remaining system (DS5.1) is essentially zero. The largest mass losses are from three systems in the SE (DS3.2, 4.2 and 4.3), which have a total loss of $-34.5 \pm$ $1.5 \mathrm{Gta}^{-1}$. System 5.3, which consists mainly of the Jakobshavn Isbræ drainage basin, shows a net mass gain due to growth in the interior that dominates the thinning near the mouth (Figs 1c and $5 \mathrm{a}$ and b), where there is ample evidence of recent rapid thinning (Abdalati and others, 2001) and reports of accelerated thinning particularly in the floating section (Thomas and others, 2003; Joughin and others, 2003).

The average $\mathrm{d} H / \mathrm{d} t$ over Greenland is $-0.75 \pm 0.35 \mathrm{~cm} \mathrm{a}^{-1}$. After correction for surface lowering due to firn compaction $\left(\mathrm{d} C / \mathrm{d} t=-1.50 \pm 0.02 \mathrm{~cm} \mathrm{a}^{-1}\right)$ and isostatic uplift $(\mathrm{d} B / \mathrm{d} t=$ $0.06 \pm 0.04 \mathrm{~cm} \mathrm{a}^{-1}$ ), the average increase in ice thickness is $0.69 \pm 0.16 \mathrm{~cm} \mathrm{a}^{-1}$ and the estimated $\mathrm{d} M / \mathrm{d} t$ is slightly positive $\left(+10.8 \pm 2.5 \mathrm{Gta}^{-1}\right)$.

In WA, most of the eastern Ross Ice Shelf drainage system (DS19) extending from the ice divide north of Byrd Station into the ice shelf, is thinning (average $\mathrm{d} l / \mathrm{d} t=$ $-0.7 \pm 0.1 \mathrm{~cm} \mathrm{a}^{-1}$ ). For example, $\mathrm{d} H / \mathrm{d} t$ is $-7.2 \pm 1.1 \mathrm{~cm} \mathrm{a}^{-1}$ at $\mathrm{MI}$ at $682 \mathrm{~m}$ just inland of MacAyeal Ice Stream. In the coastal zone from $45^{\circ} \mathrm{W}$ to $90^{\circ} \mathrm{W}$, the $\mathrm{d} H / \mathrm{d} t$ values are mostly positive on western Palmer Land (DS24) (e.g. $+35.7 \pm 3.9 \mathrm{~cm} \mathrm{a}^{-1}$ at AP) and south of the Antarctic Peninsula in the western Filchner-Ronne Ice Shelf (DS1) in the range $5-30 \mathrm{~cm} \mathrm{a}^{-1}$ (e.g. $+23.0 \pm 2.5 \mathrm{~cm} \mathrm{a}^{-1}$ at $\mathrm{Cl}$ ).

In the Pine Island (DS22) and Smith/Thwaites (DS21) systems, significant thinning is observed as previously reported (Wingham and others, 1998; Shepherd and others, 2002; Zwally and others, 2002a) with respective mass losses of $17.2 \pm 1.4$ and $45.6 \pm 1.4 \mathrm{Gta}^{-1}$, but not as large as the $84 \pm 15 \mathrm{Gta}^{-1}$ negative mass-flux estimate by Thomas and others (2004). At one location (PG2) at $627 \mathrm{~m}$ elevation on Pine Island Glacier where the average $\mathrm{d} H / \mathrm{d} t$ over the 9 years is $-68.9 \pm 3.4 \mathrm{~cm} \mathrm{a}^{-1}$, the $H(t)$ shows a tripling of thinning rate from $27 \mathrm{~cm} \mathrm{a}^{-1}$ for 1992 to March 1995 to $79 \mathrm{~cm} \mathrm{a}^{-1}$ for March 1995 to 2001 (Fig. 3b). This increase in thinning rate could be consistent with the observed increase in the velocity of Pine Island Glacier (Joughin and others, 2003; Rignot and others, 2004). However, other $H(t)$ in that region (e.g. PG at $323 \mathrm{~m}, \mathrm{TG}$ at $774 \mathrm{~m}$ and SG at $407 \mathrm{~m}$ in Fig. 3b) do not show changes in thinning rates during this period that might provide evidence of acceleration in discharge rates as implied by Thomas and others (2004).

The floating ice in WA is thinning significantly, with average $\mathrm{d} / / \mathrm{d} t$ ranging from $-8.8 \pm 5.0 \mathrm{~cm} \mathrm{a}^{-1}$ on northern Ellsworth Land (DS23) and $-10.8 \pm 1.8 \mathrm{~cm} \mathrm{a}^{-1}$ on the eastern Ross Ice Shelf (DS19) to $-216 \pm 193 \mathrm{~cm} \mathrm{a}^{-1}$ on the Pine Island system (DS22) and $-204 \pm 57 \mathrm{~cm} \mathrm{a}^{-1}$ on the Smith/ Thwaites system (DS21). Some thinning is observed on the southern part of the Filchner-Ronne Ice Shelf, but thickness increases in the $5-60 \mathrm{~cm} \mathrm{a}^{-1}$ range are dominant for the central and northern parts of the western lobe of this ice shelf. However, although $\mathrm{d} H / \mathrm{d} t$ for the point near the Ronne Ice Shelf front is positive ( $\mathrm{RI}:+5.3 \pm 2.7 \mathrm{~cm} \mathrm{a}^{-1}$ ), the first 5.5 years show a decreasing elevation followed by a sudden increase of nearly $1 \mathrm{~m}$, after the summer of 1998 when a very large open-water anomaly formed in the sea ice in front of the shelf. The open water is a likely source for a regional accumulation increase and a short-term thickening of the shelf. This large interannual variability is reflected in the relatively large $\sigma_{\mathrm{s}}$ of $\pm 50 \%$ for this location.

The $\mathrm{d} H / \mathrm{d} t$ value of $-20.4 \pm 2.0 \mathrm{~cm} \mathrm{a}^{-1}$ on the Larsen B ice shelf (LB) indicates a thinning of about $135 \mathrm{~cm} \mathrm{a}^{-1}$ prior to break-up. The $\mathrm{d} H / \mathrm{d} t=-17.9 \pm 1.8 \mathrm{~cm} \mathrm{a}^{-1}$ on the remaining Larsen C ice shelf (LC) indicates a somewhat smaller thinning of about $118 \mathrm{~cm} \mathrm{a}^{-1}$, within the range of previous analysis (Shepherd and others, 2003). The ice shelves on the western side of the Peninsula are also thinning, with $\mathrm{d} I / \mathrm{d} t=-162 \mathrm{~cm} \mathrm{a}^{-1}$ on the Wilkins Ice Shelf (WI) and $-139 \mathrm{~cm} \mathrm{a}^{-1}$ on the George VI Ice Shelf (GI). The shelves along the coast of WA from $110^{\circ} \mathrm{W}$ to $135^{\circ} \mathrm{W}$ are also thinning, with $\mathrm{d} l / \mathrm{d} t=-183 \mathrm{~cm} \mathrm{a}^{-1}$ on the west Getz Ice Shelf (WG) and $-281 \mathrm{~cm} \mathrm{a}^{-1}$ on the east Getz Ice Shelf (EG).

In $\mathrm{EA}, \mathrm{d} H / \mathrm{d} t$ are mostly in the range $\pm 5 \mathrm{~cm} \mathrm{a}^{-1}$ over the interior, with some larger values within a few hundred kilometers of the coast. The patterns of thickening or thinning tend to be spatially coherent over distances on the order of $500 \mathrm{~km}$, with a mixture of areas of thickening and thinning in contrast to the more uniform pattern of thickening recently reported (Davis and others, 2005). For example, our $H(t)$ at the upper Lambert Glacier (UL) has a uniform linear decrease $\left(-11.4 \pm 1.3 \mathrm{~cm} \mathrm{a}^{-1}\right)$ and 

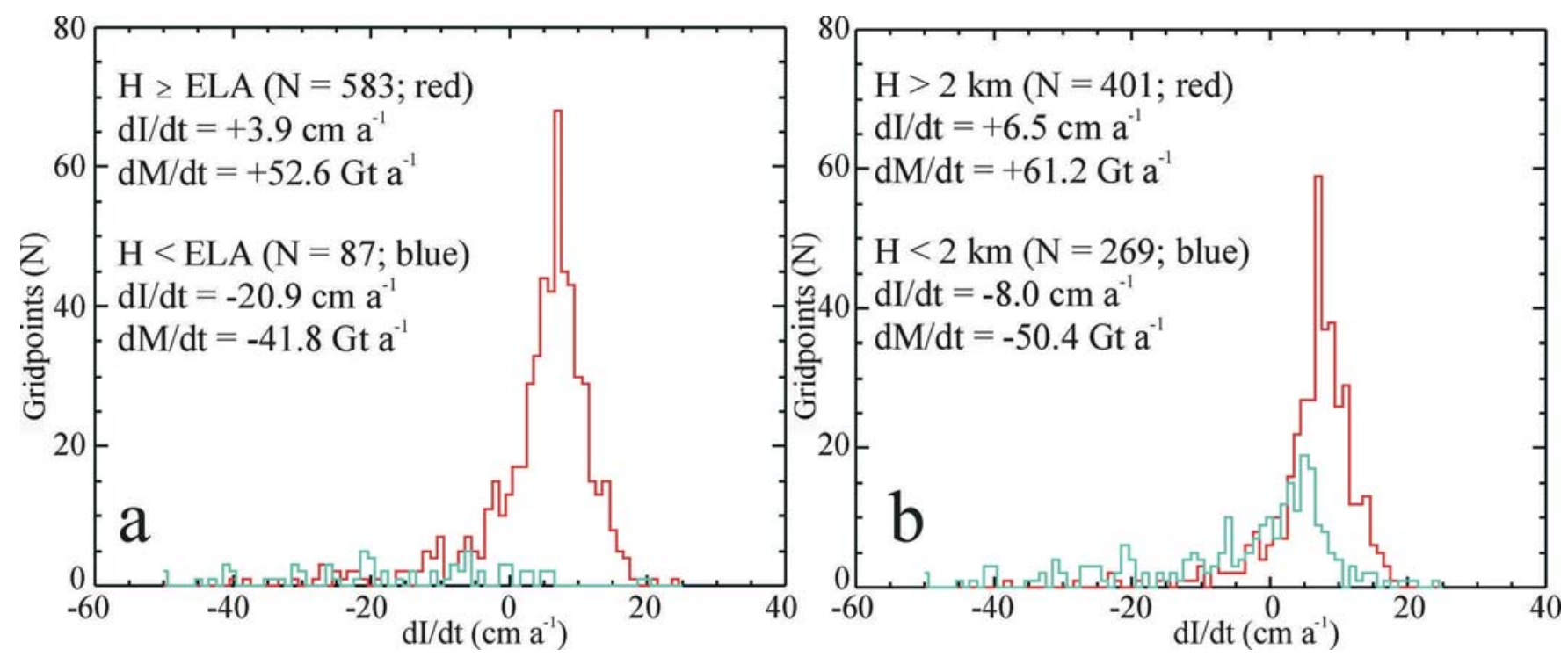

Fig. 6. Histograms of $\mathrm{d} l / \mathrm{d} t$ for Greenland: (a) above and below the ELA; and (b) above and below the $2000 \mathrm{~m}$ surface elevation contour.

many of the $\mathrm{d} H / \mathrm{d} t$ over the adjacent DS11g and $12 \mathrm{~g}$ are slightly negative (Fig. 2) compared to the significant $\mathrm{d} H / \mathrm{d} t$ increases in figure 2 of Davis and others (2005). Other sample $\mathrm{d} H / \mathrm{d} t$ at interior points are $-4.1 \pm 0.7 \mathrm{~cm} \mathrm{a}^{-1}$ over the Gamburtsev Subglacial Mountains (GM) and $+3.9 \pm 0.7 \mathrm{~cm} \mathrm{a}^{-1}$ in Dronning Maud Land (DM). In the coastal zone from $45^{\circ} \mathrm{W}$ to $180^{\circ} \mathrm{E}$, the surface elevations are mostly increasing in the range $5-20 \mathrm{~cm} \mathrm{a}^{-1}$, with exceptions including the $-11.6 \pm 3.8 \mathrm{~cm} \mathrm{a}^{-1}$ on Shirase Glacier $(\mathrm{SH}),-20.6 \pm 5.0 \mathrm{~cm} \mathrm{a}^{-1}$ on Denman Glacier (DG) and $-44.8 \pm 4.8 \mathrm{~cm} \mathrm{a}^{-1}$ on Totten Glacier (TG). Most of the floating-ice areas of EA show increases in elevation, including $+15.0 \pm 1.7 \mathrm{~cm} \mathrm{a}^{-1}$ on the Amery Ice Shelf (AI) and $+8.6 \pm 0.6 \mathrm{~cm} \mathrm{a}^{-1}$ on the western Ross Ice Shelf (WR). The pattern of changes on the Ross Ice Shelf is clearly delineated by the drainage systems, with marked thickening of the ice flowing from EA and thinning of the ice from WA.

Our average thickening for EA $\left(\mathrm{d} / / \mathrm{d} t=+0.2 \pm 0.1 \mathrm{~cm} \mathrm{a}^{-1}\right)$ is smaller than the $1.8 \pm 0.3 \mathrm{~cm} \mathrm{a}^{-1}$ rate reported in Davis and others (2005), which would be $1.6 \mathrm{~cm} \mathrm{a}^{-1}$ if adjusted for our calculated slowing of firn compaction $\left(\mathrm{d} C / \mathrm{d} t=0.21 \mathrm{~cm} \mathrm{a}^{-1}\right)$. Although their $\mathrm{d} l / \mathrm{d} t$ is eight times as large, their $\mathrm{d} M / \mathrm{d} t$ increase is only three times as large due to their low estimated density for the added mass as discussed above. While some of the difference may be due to respective methods of constructing the $H(t)$ time series or our interpolated gridpoints, a more likely cause is difference in the methods of time-series analysis to derive $\mathrm{d} H / \mathrm{d} t$. We believe our calculated $\mathrm{d} H / \mathrm{d} t$ more accurately represent the changes in elevation during the measurement period than the results of the autoregression method (Ferguson and others, 2004), which may remove interannual variability and misrepresent the actual change during the measurement period. In this regard, we note that the long-term change in figure 1 of Davis and others (2005) over the measurement period appears smaller than their derived linear trend.

The average $\mathrm{d} H / \mathrm{d} t$ increase over the total Antarctic grounded ice is only $+0.18 \pm 0.11 \mathrm{~cm} \mathrm{a}^{-1}$. After correction for the small surface lowering due to firn compaction $\left(\mathrm{d} C / \mathrm{d} t=-0.08 \pm 0.006 \mathrm{~cm} \mathrm{a}^{-1}\right)$ and isostatic uplift $\left(\mathrm{d} B / \mathrm{d} t=0.54 \pm 0.007 \mathrm{~cm} \mathrm{a}^{-1}\right)$, the average decrease in ice thickness is $0.28 \pm 0.11 \mathrm{~cm} \mathrm{a}^{-1}$. The changes in WA grounded ice are significantly larger $(\mathrm{d} / / \mathrm{d} t=-2.6 \pm$ $0.3 \mathrm{~cm} \mathrm{a}^{-1}$ and $\mathrm{d} / \mathrm{M} / \mathrm{d} t=-46.6 \pm 4.4 \mathrm{Gta}^{-1}$ ) than those in EA $\left(\mathrm{d} / / \mathrm{d} t=+0.2 \pm 0.1 \mathrm{~cm} \mathrm{a}^{-1}\right.$ and $\mathrm{d} M / \mathrm{d} t=+16.3 \pm$ $\left.10.7 \mathrm{Gta}^{-1}\right)$, and the overall balance of grounded ice is negative $\left(\mathrm{d} / \mathrm{M} / \mathrm{d} t=-30.3 \pm 12.1 \mathrm{Gta}^{-1}\right)$. The changes in floating ice are large in both WA $(\mathrm{d} l / \mathrm{d} t=-13.9 \pm$ $1.7 \mathrm{~cm} \mathrm{a}^{-1}$ and $\left.\mathrm{d} / \mathrm{M} / \mathrm{d} t=-94.5 \pm 11.4 \mathrm{Gt} \mathrm{a}^{-1}\right)$ and $\mathrm{EA}(\mathrm{d} / / \mathrm{d} t=$ $+22.6 \pm 1.5 \mathrm{~cm} \mathrm{a}^{-1}$ and $+142 \pm 10 \mathrm{Gt} \mathrm{a}^{-1}$ ), with signs corresponding to the respective loss and gain of grounded ice.

Although the overall average ice-thickness changes are small, average $\mathrm{d} l / \mathrm{d} t$ in particular DS are large (Fig. 4a; Table 2). In Greenland, average $\mathrm{d} l / \mathrm{d} t$ range from $+7.6 \pm$ $0.6 \mathrm{~cm} \mathrm{a}^{-1}$ in DS4. 1 in the southeast and $+7.1 \pm 0.2 \mathrm{~cm} \mathrm{a}^{-1}$ in Jakobshavn DS5.3 in the southwest to $-14.6 \pm 1.5 \mathrm{~cm} \mathrm{a}^{-1}$ in DS4.2 and $-27.3 \pm 0.7 \mathrm{~cm} \mathrm{a}^{-1}$ in DS4.3 in the southeast. In WA, average $\mathrm{d} / \mathrm{d} t$ on grounded ice range from $+4.0 \pm 0.2 \mathrm{~cm} \mathrm{a}^{-1}$ in the central Ross Ice Shelf DS18 to $-22.9 \pm 0.7 \mathrm{~cm} \mathrm{a}^{-1}$ in the Smith and Thwaites DS21. In EA, average $\mathrm{d} l / \mathrm{d} t$ on grounded ice range from $+7.4 \pm 1.0 \mathrm{~cm} \mathrm{a}^{-1}$ in west Dronning Maud Land DS5 to $-14.5 \pm 2.7 \mathrm{~cm} \mathrm{a}^{-1}$ in Kemp Land DS8. In WA, average $\mathrm{d} / / \mathrm{d} t$ on floating ice range from $+21.8 \pm 1.2 \mathrm{~cm} \mathrm{a}^{-1}$ on the Filchner-Ronne Ice Shelf DS1 to $-204 \pm 57 \mathrm{~cm} \mathrm{a}^{-1}$ in the Smith and Thwaites DS21 and $-216 \pm 193 \mathrm{~cm} \mathrm{a}^{-1}$ in the Pine Island DS22. In EA, average $\mathrm{d} / \mathrm{d} t$ on floating ice range from $+91.5 \pm 10.7 \mathrm{~cm} \mathrm{a}^{-1}$ in the Davis Sea DS12, $+59.2 \pm 8.3 \mathrm{~cm} \mathrm{a}^{-1}$ on the west Dronning Maud Land DS5, and $+55.1 \pm 5.4 \mathrm{~cm} \mathrm{a}^{-1}$ on the central Amery Ice Shelf DS10 to $-90.3 \pm 20.5 \mathrm{~cm} \mathrm{a}^{-1}$ in Terre Adélie DS14. The dominance of negative balances on both floating and grounded ice in WA, and the dominance of positive balances on both floating and grounded ice in EA are illustrated in Figure 4.

\section{DISCUSSION OF OVERALL MASS CHANGES AND EFFECT ON SEA LEVEL}

Of the three ice sheets, WA shows the largest imbalance $\left(\mathrm{d} M / \mathrm{d} t=-47 \pm 4 \mathrm{Gta}^{-1}\right)$, which is partially offset by a positive balance in EA $\left(+16 \pm 11 \mathrm{Gta}^{-1}\right)$, for a net loss of grounded ice from Antarctica $\left(-31 \pm 12 \mathrm{Gta}^{-1}\right)$ contributing $+0.08 \pm 0.03 \mathrm{~mm} \mathrm{a}^{-1}$ to sea-level change. The loss from Antarctica is partially compensated by a small gain in 
Greenland $\left(+11 \pm 3 \mathrm{Gta}^{-1}\right)$ contributing $-0.03 \pm 0.01 \mathrm{~mm} \mathrm{a}^{-1}$ to sea-level change, for net mass loss of $20 \pm 12 \mathrm{Gt} \mathrm{a}^{-1}$ and a combined sea-level contribution from the three ice sheets of $+0.05 \pm 0.03 \mathrm{~mm} \mathrm{a}^{-1}$. The small mass gain in Greenland is contrary to the widely held view that Greenland is losing significant mass during approximately the same period, but is consistent (within the range of errors) with our reinterpretation of the ATM-based results that indicate the ice sheet was close to balance $\left(-8 \mathrm{Gt} \mathrm{a}^{-1}\right)$. The loss from WA and the gain in EA are remarkably consistent with the respective values of $-48 \pm 14$ and $+22 \pm 23 \mathrm{Gt} \mathrm{a}^{-1}$ from mass-flux analysis of only about $50 \%$ of the Antarctic outlet glaciers under the assumption of only a $5 \%$ uncertainty in accumulation rates (Rignot and Thomas, 2002).

The contribution to sea-level change is small relative to the potential contribution from ice sheets, not only in relation to the bulk of grounded ice that lies above sea level, but also in relation to the mass flux across the ice-air interface. The loss in Antarctica and the gain in Greenland are each less than about $3 \%$ of the respective surface balance estimates, or together less than $1 \%$ of the total mass input. The uncertainties are also significantly less than those noted in Huybrechts and others (2001). The contribution of the ice sheets is also small compared to the most recent estimate of current sea-level rise of $2.8 \pm 0.4 \mathrm{~mm} \mathrm{a}^{-1}$ from satellite altimetry (Leuliette and others, 2004), which further confounds possible explanations of the causes of contemporary sea-level rise.

We include estimates of $\mathrm{d} F / \mathrm{d} t$ (Table 1 ) for the end-point assumption that the observed $\mathrm{d} / \mathrm{d} t$ are occurring only in the firn due to short-term changes in precipitation and that the dynamic balance terms are zero, except in the ablation zone of Greenland where firn compaction is neglected. While there is evidence for decadal changes in precipitation such as the $4 \%$ per decade increase in Greenland shown by Box and others (in press) and the long-term trends in Antarctic accumulation mentioned below, we believe evidence of short-term changes over the ice sheets to support this assumption is lacking. Nevertheless, under this assumption, the small mass gain of $11 \pm 3 \mathrm{Gta}^{-1}$ in Greenland would be changed to a small mass loss of $18 \pm 2 \mathrm{Gta}^{-1}$, because the assumption reduces the estimated gain above the ELA but does not change the loss below the ELA. In Antarctica, the assumption would reduce the mass loss from $31 \pm 12 \mathrm{Gta}^{-1}$ to $14 \pm 5 \mathrm{Gta}^{-1}$. The resulting net loss from the three ice sheets would be increased from $20 \pm 12 \mathrm{Gta}^{-1}$ to $32 \pm$ $6 \mathrm{Gta}^{-1}$, giving a slightly larger combined sea-level contribution of $+0.09 \pm 0.02 \mathrm{~mm} \mathrm{a}^{-1}$.

The small positive $\mathrm{d} / / \mathrm{d} t$ averaged over EA is consistent with evidence of multi-decadal increasing trends in accumulation from ice cores (Mosley-Thompson and others, 1999; Wen and others, 2001; Goodwin and others, 2003) and modeling estimates of long-term trends in Antarctic precipitation (Smith and others, 1998). In particular, ice growth in the region of the Antarctic Peninsula may also be due to increasing precipitation during the last century (Smith and others, 1998). The marked thinnings in the Pine Island and Thwaites Glacier basins of WA and the Totten Glacier basin in EA are probably ice-dynamic responses to long-term climate change and perhaps past removal of adjacent ice shelves. The correlation between the mass changes of grounded and floating ice in EA and WA may suggest a coherent response of grounded and floating ice to atmospheric and oceanic forcings. The thinning of ice shelves in
WA may be fostering increased outflow, and the thickening of ice shelves in EA may be contributing to reduced outflow.

In Greenland, most drainage systems have small mass gains or losses, with the largest mass losses from three systems in the southeast. The most significant division in $\mathrm{d} M / \mathrm{d} t$ values is between the accumulation zone with a gain of $52.6 \pm 1.8 \mathrm{Gta}^{-1}$ above the ELA and the ablation zone with a loss of $41.8 \pm 1.8 \mathrm{Gta}^{-1}$ below the ELA (Fig. 5). The gain above $2000 \mathrm{~m}$ elevation is $61.2 \pm 0.6 \mathrm{Gt} \mathrm{a}^{-1}$ and the loss below $2000 \mathrm{~m}$ is $50.4 \pm 2.5 \mathrm{Gt} \mathrm{a}^{-1}$. These changes indicate a gradual steepening of the ice sheet as expected with climate warming, at a greater rate than previously indicated by the ATM results.

Although the finding of near balance in Greenland might be interpreted to mitigate concern about the future contributions of the ice sheets to sea-level rise, the findings indicate that significant climate-induced changes are taking place. Furthermore, recent ATM surveys indicate a recent increase in coastal thinning (Krabill and others, 2004), but additional attention needs to be given to effects of increasing precipitation both inland and in coastal regions (Bromwich and others, 2001; Hanna and others, 2001; Box and others, in press). The extent to which the competing processes of inland growth will continue to balance coastal shrinkage, until shrinkage under the predicted climate warming becomes dominant (Huybrechts and others, 2004), will be seen as observations continue and model predictions are validated or improved.

While the overall net mass changes are small, the changes are generally much larger in particular drainage systems (Table 2; Fig. 4b). Moreover, the ratio of net mass changes to surface balance estimates in many drainage systems (Figs 10 and 12 in Appendix) are up to three orders of magnitude larger than the overall ice-sheet ratios of mass change to mass input (Table 2: $(\mathrm{d} M / \mathrm{d} t) / A_{j j} ;$ Fig. 12). For example, DS5 in west Dronning Maud Land and DS9 to the west of the Amery Ice Shelf in EA have positive mass balances of $49 \%$ and $43 \%$ respectively over their mass inputs. In contrast, DS21 (Smith and Thwaites Glaciers) and DS22 (Pine Island Glacier) in WA have negative mass balances of $66 \%$ and $21 \%$ respectively over their mass inputs. In Greenland, DS4.1 in the southeast has a positive balance of $690 \%$, suggesting a large underestimate of the accumulation rate in that system, whereas the adjacent DS3.2 to the north has a negative balance of $110 \%$, and the adjacent DS4.2 to the south has a negative balance of over $1000 \%$. This wide disparity in regional mass balances clearly illustrates the risks of sampling strategies based on studying only the places where the largest changes are taking place.

Overall, our results describe the ice-sheet mass balance during essentially the last decade of the 20th century, and thus provide a baseline for evaluating future changes. Although non-linear variations in $H(t)$ for periods of 3-5 years are evident in some regions, we believe the linear character of most of the $\mathrm{d} H / \mathrm{d} t$ trends suggests a dominance of multi-decadal mass-balance processes during this period. Clearly, these factors are expected to change (Huybrechts and others, 2004), perhaps at a greater rate than has been predicted, as recent measurements of increased outflow and increasing precipitation in Greenland may be indicating (Alley and others, 2003). Therefore, continued comprehensive monitoring of ice elevations is essential to determine, in particular, the relative importance of increasing summer 
temperatures on both ice melting and dynamic thinning compared to the effect of increasing precipitation on both inland growth and reduction of ablation at lower elevations.

\section{ACKNOWLEDGEMENTS}

We thank the European Space Agency for our selection as ERS investigators and for providing the radar altimeter data and technical information. Data processing and analysis was supported by NASA's Cryospheric Sciences Program and by ICESat Project Science. We appreciate comments and suggestions from reviewer R.B. Alley and from R.J. Braithwaite. We thank P. Huybrechts, E. Ivins and R. Peltier for digital copies of their bedrock motion data, W. Krabill for a digital copy of the ATM-based $\mathrm{d} H / \mathrm{d} t$ map, J. Comiso for the digital temperature data, D. Vaughan for digital surface balance data for the Larsen Ice Shelf and I. Allison for his suggestion to account for sea-level rise in calculation of iceshelf thickness changes.

\section{REFERENCES}

Abdalati, W. and 9 others. 2001. Outlet glacier and margin elevation changes: near-coastal thinning of the Greenland ice sheet. J. Geophys. Res., 106(D24), 33,729-33,742.

Alley, R.B. and 10 others. 2003. Abrupt climate change. Science, 299(5615), 2005-2010.

Arthern, R.J. and D.J. Wingham. 1998. The natural fluctuations of firn densification and their effect on the geodetic determination of ice sheet mass balance. Climatic Change, 40(4), 605-624.

Benson, C.S. 1962. Stratigraphic studies in the snow and firn of the Greenland ice sheet. SIPRE Res. Rep. 70.

Box, J.E. and 8 others. In press. Greenland ice sheet surface mass balance variability (1988-2004) from calibrated polar MM5 output. J. Climate.

Braithwaite, R.J. 1994. Thoughts on monitoring the effects of climate change on the surface elevation of the Greenland ice sheet. Global Planet. Change, 9(3-4), 251-261.

Braithwaite, R.J. and Y. Zhang. 2000. Sensitivity of mass balance of five Swiss glaciers to temperature changes assessed by tuning a degree-day model. J. Glaciol., 46(152), 7-14.

Bromwich, D.H., Q.S. Chen, L.S. Bai, E.N. Cassano and Y. Li. 2001. Modeled precipitation variability over the Greenland ice sheet. J. Geophys. Res., 106(D24), 33,891-33,908.

Comiso, J.C. 2003. Warming trends in the Arctic from clear satellite observations. J. Climate, 16(21), 3498-3510.

Comiso, J.C. and C.L. Parkinson. 2004. Satellite-observed changes in the Arctic. Phys. Today, 57(8), 38-44.

Davis, C.H., Y. Li, J.R. McConnell, M.M. Frey and E. Hanna. 2005. Snowfall-driven growth in East Antarctic ice sheet mitigates recent sea-level rise. Science, 308(5730), 1898-1901.

Dibb, J.E. and M. Fahnestock. 2004. Snow accumulation, surface height change, and firn densification at Summit, Greenland: insights from 2 years of in situ observation. J. Geophys. Res., 109(D24), D24113. (10.1029/2003JD004300.)

Femenias, P. 1996. ERS QLOPR and OPR range processing. ESA ESRIN Tech. Note ER-TN-RS-RA-0022. Frascati, European Space Agency/European Space Research Institute.

Ferguson, A.C., C.H. Davis and J.E. Cavanaugh. 2004. An autoregressive model for analysis of ice sheet elevation change time series. IEEE Trans. Geosci. Remote Sens., 42(11), 2426-2436.

Giovinetto, M.B. and H.J. Zwally. 2000. Spatial distribution of net surface accumulation on the Antarctic ice sheet. Ann. Glaciol., 31, 171-178.

Goodwin, I., H. De Angelis, M. Pook and N.W. Young. 2003. Snow accumulation variability in Wilkes Land, East Antarctica and the relationship to atmospheric ridging in the $130^{\circ}-170^{\circ} \mathrm{E}$ region since 1930. J. Geophys. Res., 108(D21), 4673. (10.1029/ 2002JD002995.)

Hamilton, G.S., I.M. Whillans and P.J. Morgan. 1998. First point measurements of ice-sheet thickness change in Antarctica. Ann. Glaciol., 27, 125-129.

Hanna, E., P. Valdes and J. McConnell. 2001. Patterns and variations of snow accumulation over Greenland, 1979-98, from ECMWF analyses and their verification. J. Climate, 14(17), 3521-3535.

Huybrechts, P. 2002. Sea-level changes at the LGM from icedynamic reconstructions of the Greenland and Antarctic ice sheets during the glacial cycles. Quat. Sci. Rev., 21(1-3), 203-231.

Huybrechts, P., M. Kuhn, K. Lambeck, M.T. Nhuan, D. Qin and P.L. Woodworth. 2001. Changes in sea level. In Houghton, J.T. and 7 others, eds. Climate change 2001: the scientific basis. Contribution of Working Group I to the Third Assessment Report of the Intergovernmental Panel on Climate Change. Cambridge, Cambridge University Press, 639-694.

Huybrechts, P., J. Gregory, I. Janssens and M. Wild. 2004. Modelling Antarctic and Greenland volume changes during the 20th and 21 st centuries forced by GCM time slice integrations. Global Planet. Change, 42(1-4), 83-105.

Ivins, E.R., X. Wu, C.A. Raymond, C.F. Yoder and T.S. James. 2001. Temporal geoid of a rebounding Antarctica and potential measurement by the GRACE and GOCE satellites. In Sideris, M.G., ed. Gravity, Geoid and Geodynamics 2000: GGG2000 IAG International Symposium, Banff, Alberta, Canada, July 31August 4, 2000. Berlin, Springer, 361-366. (International Association of Geodesy Symposia 123.)

Johannessen, O.M., K. Khvorostovsky, M.W. Miles and L.P. Bobylev. 2005. Recent ice-sheet growth in the interior of Greenland. Science, 310(5750), 1013-1016.

Joughin, I., E. Rignot, C.E. Rosanova, B.K. Lucchitta and J. Bohlander. 2003. Timing of recent accelerations of Pine Island Glacier, Antarctica. Geophys. Res. Lett., 30(13), 1706 (10.1029/ 2003GL017609.)

Joughin, I., W. Abdalati and M. Fahenstock. 2004. Large fluctuations in speed on Greenland's Jakobshavn Isbrae glacier. Nature, 432, 608-610.

Kapsner, W.R., R.B. Alley, C.A. Shuman, S. Anandakrishnan and P.M. Grootes. 1995. Dominant influence of atmospheric circulation on snow accumulation in Greenland over the past 18,000 years. Nature, 373(6509), 52-54.

Kojima, K. 1964. Densification of snow in Antarctica. In Mellor, M., ed. Antarctic snow and ice studies. Washington, DC, American Geophysical Union, 157-218. (Antarctic Research Series 2.)

Krabill, W.B. and 9 others. 2000. Greenland ice sheet: highelevation balance and peripheral thinning. Science, 289(5478), 428-430.

Krabill, W. and 12 others. 2004. Greenland Ice Sheet: increased coastal thinning. Geophys. Res. Lett., 31(24), L24402. (10.1029/ 2004GL021533.)

Leuliette, E.W., R.S. Nerem and G.T. Mitchum. 2004. Calibration of TOPEX/Poseidon and Jason altimeter data to construct a continuous record of mean sea level change. Marine Geodesy, 27(1-2), 79-94.

Li, J. and H.J. Zwally. 2002. Modeled seasonal variations of firn density induced by steady-state surface air-temperature cycle. Ann. Glaciol., 34, 299-302.

Li, J. and H.J. Zwally. 2004. Modeling the density variation in shallow firn layer. Ann. Glaciol., 38, 309-313.

Li, J., H.J. Zwally, H. Cornejo and D. Yi. 2003. Seasonal variation of snow-surface elevation in North Greenland as modeled and detected by satellite radar altimetry. Ann. Glaciol., 37, 233-238.

McConnell, J.R. and 6 others. 2001. Annual net snow accumulation over southern Greenland from 1975 to 1998. J. Geophys. Res., 106(D24), 33,827-33,838. 
Monaghan, A.J., D.H. Bromwich and S.-H. Wang. In press. Recent trends in Antarctic snow accumulation from Polar MM5. Philos. Trans. Royal Soc. A.

Mosley-Thompson, E., J.F. Paskievitch, A.J. Gow and L.G. Thompson. 1999. Late 20th century increase in South Pole snow accumulation. J. Geophys. Res., 104(D4), 3877-3886.

Peltier, W.R. 2004. Global glacial isostatic adjustment and the surface of the ice-age Earth: the ICE-5G(VM2) model and GRACE. Annu. Rev. Earth Planet. Sci., 32, 111-149.

Reeh, N., D.A. Fisher, R.M. Koerner and H.B. Clausen. In press. An empirical firn-densification model comprising ice lenses. Ann. Glaciol.

Rignot, E. and R.H. Thomas. 2002. Mass balance of polar ice sheets. Science, 297(5586), 1502-1506.

Rignot, E., G. Casassa, P. Gogineni, W. Krabill, A. Rivera and R. Thomas. 2004. Accelerated ice discharge from the Antarctic Peninsula following the collapse of Larsen B ice shelf. Geophys. Res. Lett., 31(18), L18401. (10.1029/2004GL020697.)

Scambos, T.A., J.A. Bohlander, C.A. Shuman and P. Skvarca. 2004. Glacier acceleration and thinning after ice shelf collapse in the Larsen B embayment, Antarctica. Geophys. Res. Lett., 31(18), L18402. (10.1029/2004GL020670.)

Scharroo, R. and P. Visser. 1998. Precise orbit determination and gravity field improvement for the ERS satellites. J. Geophys. Res., 103(C4), 8113-8127.

Shepherd, A., D. Wingham and J.A. Mansley. 2002. Inland thinning of the Amundsen Sea sector, West Antarctica. Geophys. Res. Lett., 29(10), 1364. (10.1029/2001GL014183.)

Shepherd, A., D. Wingham, T. Payne and P. Skvarca. 2003. Larsen ice shelf has progressively thinned. Science, 302 (5646), 856-859.

Skvarca, P., W. Rack, H. Rott and T. Donángelo. 1999. Climatic trend and the retreat and disintegration of ice shelves on the Antarctic Peninsula: an overview. Polar Res., 18(2), 151-157.

Smith, I.N., W.F. Budd and P. Reid. 1998. Model estimates of Antarctic accumulation rates and their relationship to temperature changes. Ann. Glaciol., 27, 246-250.

Thomas, R.H. 2003. Force-perturbation analysis of recent thinning and acceleration of Jakobshavn Isbræ, Greenland. J. Glaciol., 50(168), 57-66.

Thomas, R. and 7 others. 2001. Mass balance of higher-elevation parts of the Greenland ice sheet. J. Geophys. Res., 106(D24), 33,707-33,716.

Thomas, R.H., W. Abdalati, E. Frederick, W.B. Krabill, S. Manizade and K. Steffen. 2003. Investigation of surface melting and dynamic thinning on Jakobshavn Isbræ, Greenland. J. Glaciol., 49(165), 231-239.
Thomas, R. and 17 others. 2004. Accelerated sea level rise from West Antarctica. Science, 306 (5694), 255-258.

Vaughan, D.G., J.L. Bamber, M.B. Giovinetto, J. Russell and A.P.R. Cooper. 1999. Reassessment of net surface mass balance in Antarctica. J. Climate, 12(4), 933-946.

Wen, J. and 6 others. 2001. Snow density and stratigraphy at DT001 in Princess Elizabeth Land, East Antarctica. Polar Meteorol. Glaciol., 15(43), 43-54.

Whillans, I.M. 1977. The equation of continuity and its application to the ice sheet near 'Byrd' Station, Antarctica. J. Glaciol., 18(80), 359-371.

Whitworth, T., III, A.H. Orsi, S.J. Kim and W.D. Nowlin, Jr. 1998. Water masses and mixing near the Antarctic Slope front. In Jacobs, S.S. and R.F. Weiss, eds. Ocean, ice and atmosphere: interactions at the Antarctic continental margin. Washington, DC, American Geophysical Union, 1-27. (Antarctic Research Series 75.)

Wingham, D.J., A.L. Ridout, R. Scharroo, R.J. Arthern and C.K. Shum. 1998. Antarctic elevation change 1992 to 1996. Science, 282(5388), 456-458.

Zwally, H.J. 1989. Growth of Greenland ice sheet: interpretation. Science, 246(4937), 1589-1591.

Zwally, H.J. and A.C. Brenner. 2001. Ice sheet dynamics and mass balance. In Fu, L.-L. and A. Cazanave, eds. Satellite altimetry and earth sciences. New York, Academic Press Inc., 351-369. (International Geophysical Series 69.)

Zwally, H.J. and M.B. Giovinetto. 2000. Spatial distribution of net surface mass balance on Greenland. Ann. Glaciol., 31, 126-132.

Zwally, H.J. and M.B. Giovinetto. 2001. Balance mass flux and ice velocity across the equilibrium line in drainage systems of Greenland. J. Geophys. Res., 106(D24), 33,71733,728 .

Zwally, H.J. and J. Li. 2002. Seasonal and interannual variations of firn densification and ice-sheet surface elevation at Greenland summit. J. Glaciol., 48(161), 199-207.

Zwally, H.J. and 15 others. 2002a. ICESat's laser measurements of polar ice, atmosphere, ocean and land. J. Geodyn., 34(3-4), 405-445.

Zwally, H.J., M.A. Beckley, A.C. Brenner and M.B. Giovinetto. 2002b. Motion of major ice-shelf fronts in Antarctica from slantrange analysis of radar altimeter data, 1978-98. Ann. Glaciol., 34, 255-262.

Zwally, H.J., W. Abdalati, T. Herring, K. Larson, J. Saba and K. Steffen. 2002c. Surface melt-induced acceleration of Greenland ice-sheet flow. Science, 297(5579), 218-222. 


\section{APPENDIX}

a
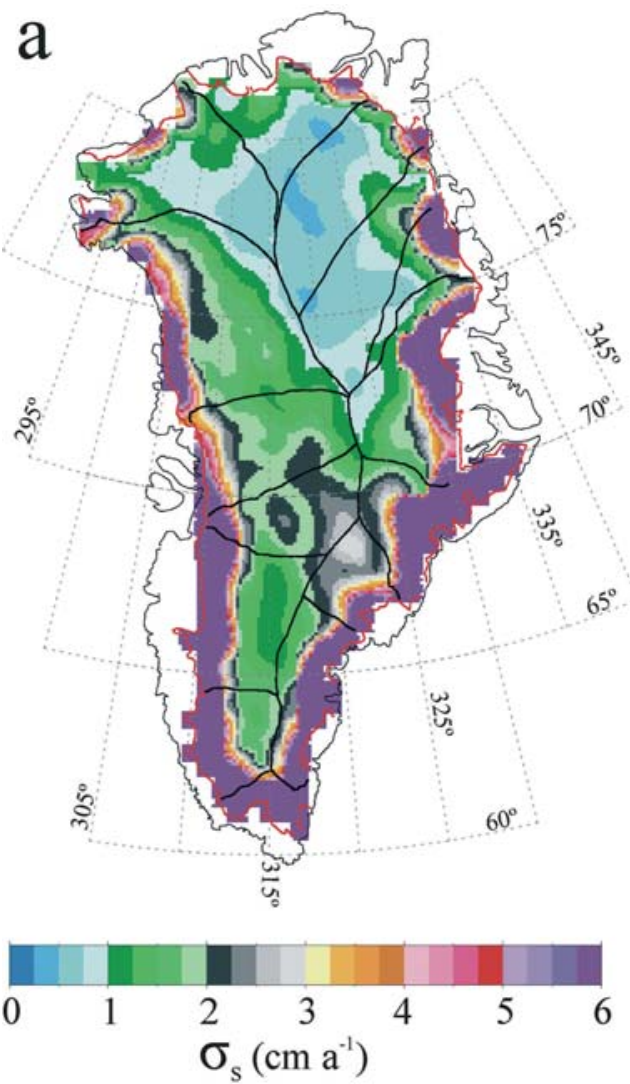
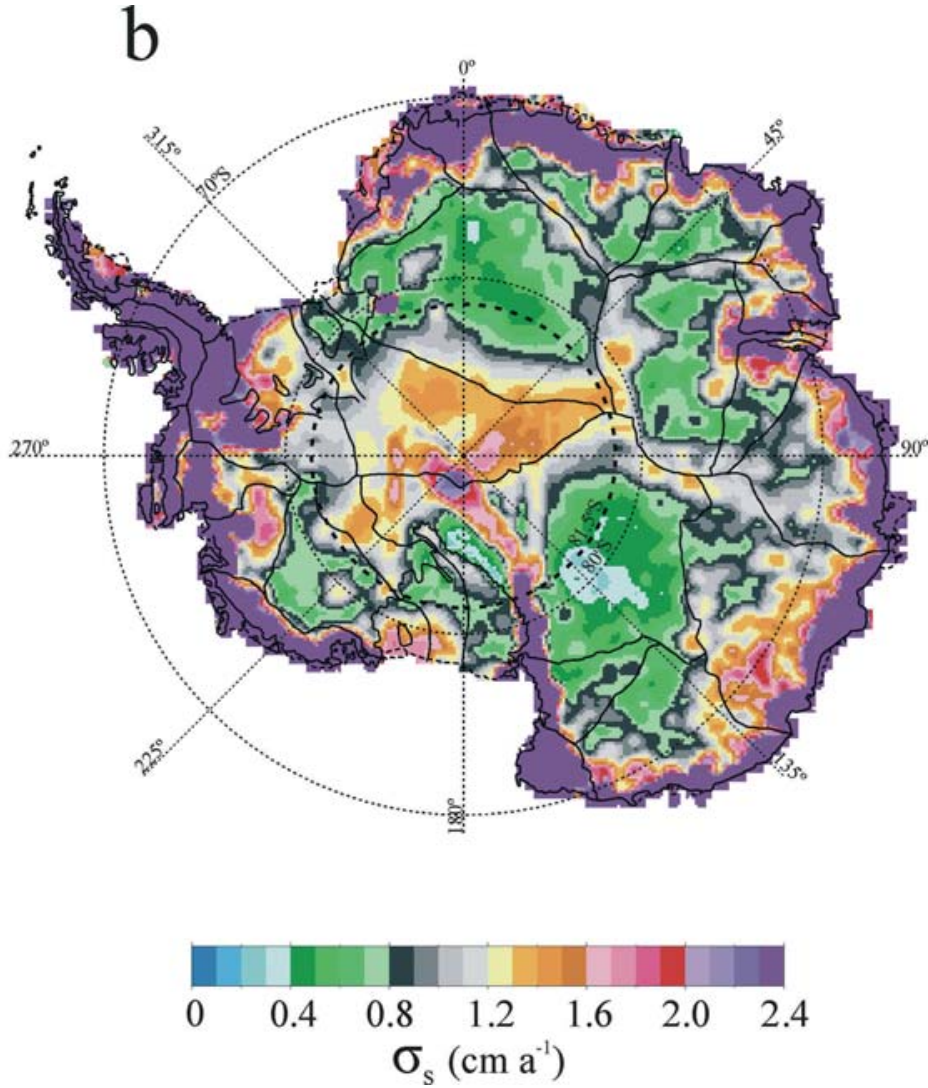

Fig. 7. Distribution of $\sigma_{\mathrm{s}}$ of the derived $\mathrm{d} H / \mathrm{d} t$ from ERS data for Greenland (a) and Antarctica (b) as described in the text.
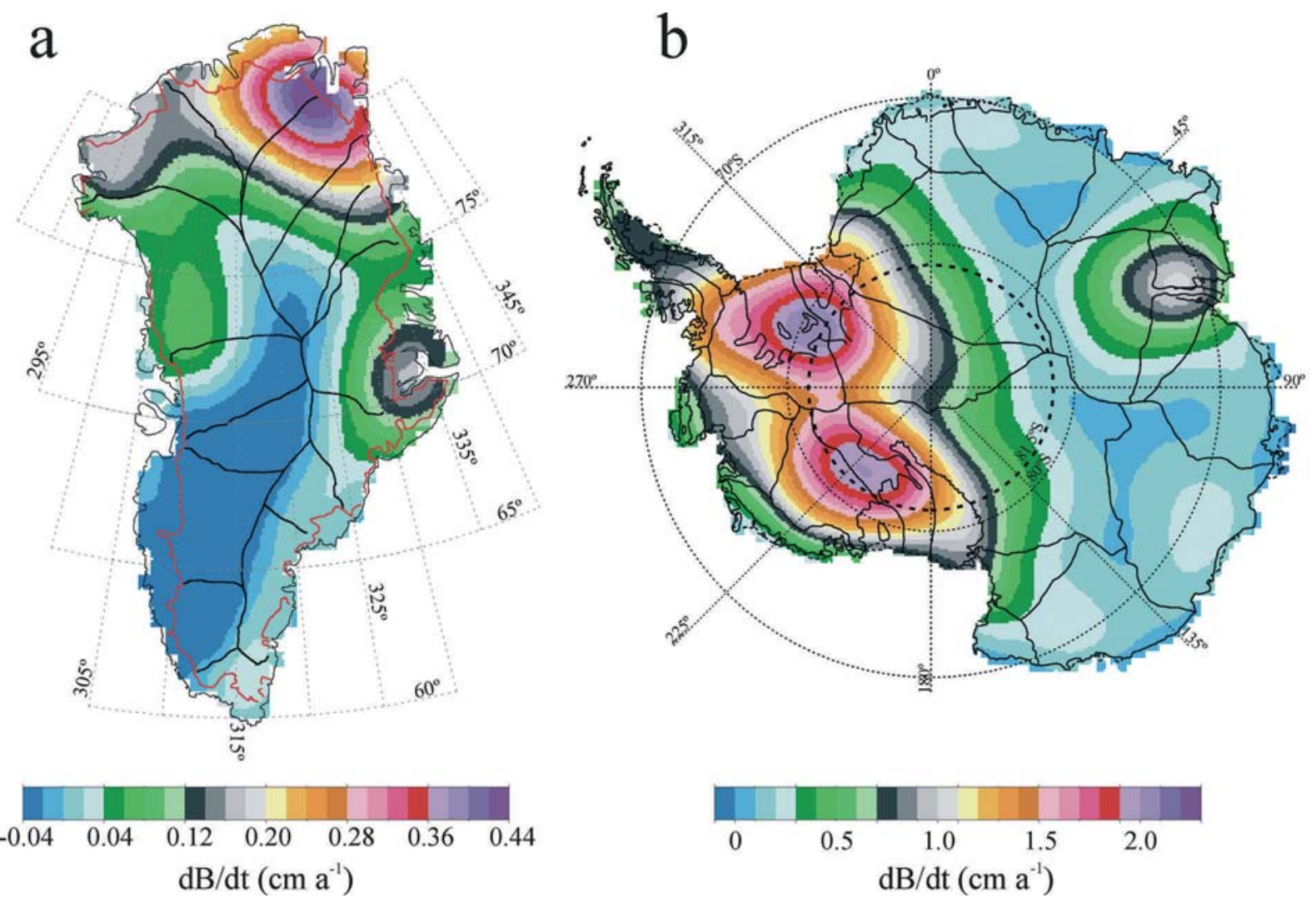

Fig. 8. Distribution of $d B / d t$ for Greenland (a) and Antarctica (b) as described in the text. 
a
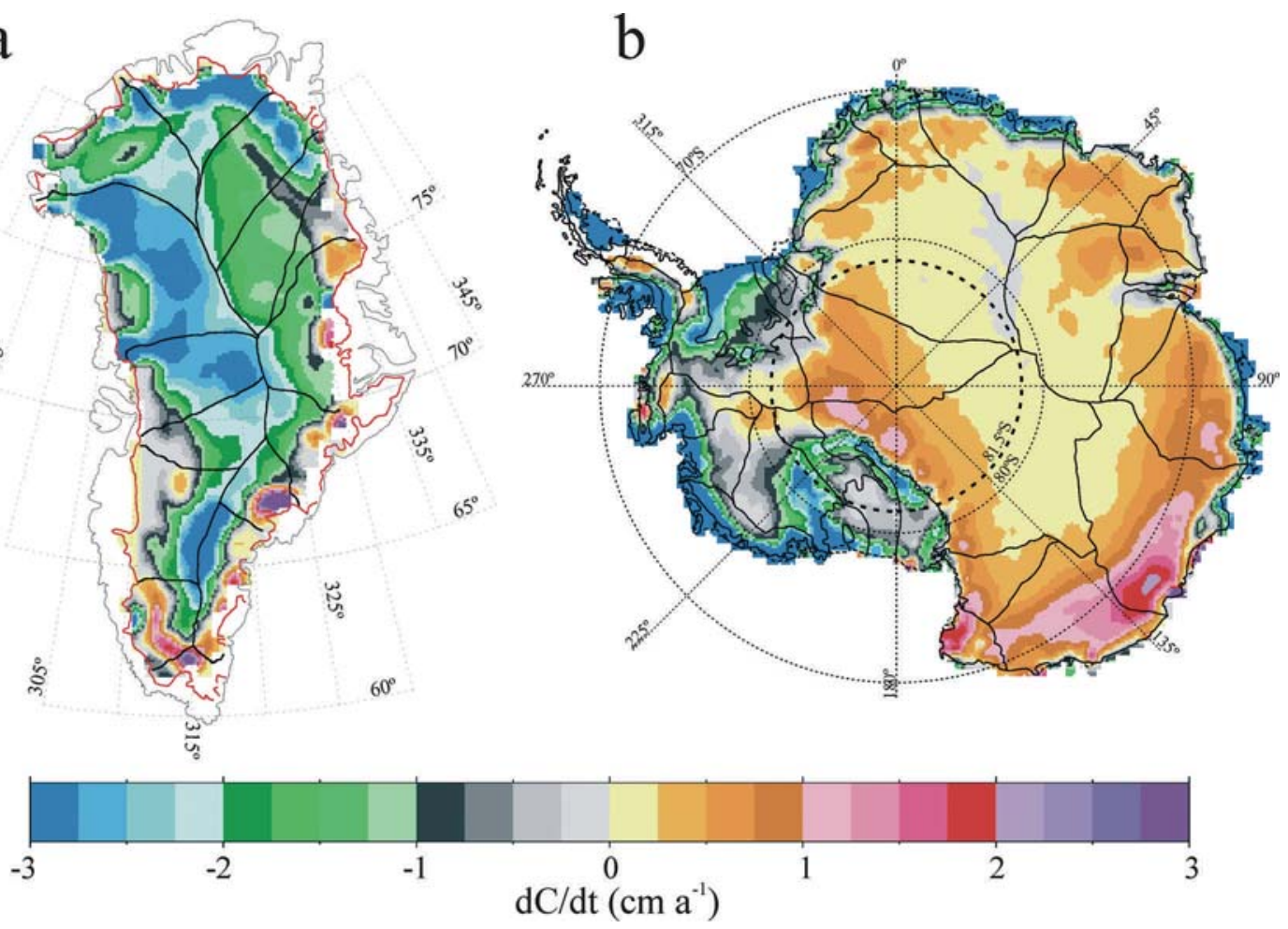

Fig. 9. Distribution of $\mathrm{d} C / \mathrm{d} t$ in Greenland (a) and Antarctica (b) calculated with a temperature-driven firn compaction model as described in the text. The firn compaction reduces the surface elevation over the Greenland accumulation zone by $1.71 \mathrm{~cm} \mathrm{a}^{-1}$ as the result of climate warming during the measurement period. In WA, the lowering on grounded ice is $1.58 \mathrm{~cm} \mathrm{a}^{-1}$ and the lowering on floating ice is $2.79 \mathrm{~cm} \mathrm{a}^{-1}$, also due to regional warming, as is the $1.70 \mathrm{~cm} \mathrm{a}^{-1}$ lowering on EA floating ice. In EA grounded ice, a small $0.21 \mathrm{~cm} \mathrm{a}^{-1}$ surface rise is caused by a small cooling over the inland ice. The $\mathrm{d} C / \mathrm{d} t$ are computed for all points where $A$ is $>25 \mathrm{~kg} \mathrm{~m}^{-2} \mathrm{a}^{-1}$, which in Greenland excluded 121 gridpoints mostly located in the ablation zone, and in Antarctica excluded 92 gridpoints mostly located in the interior of EA where accumulation is small.
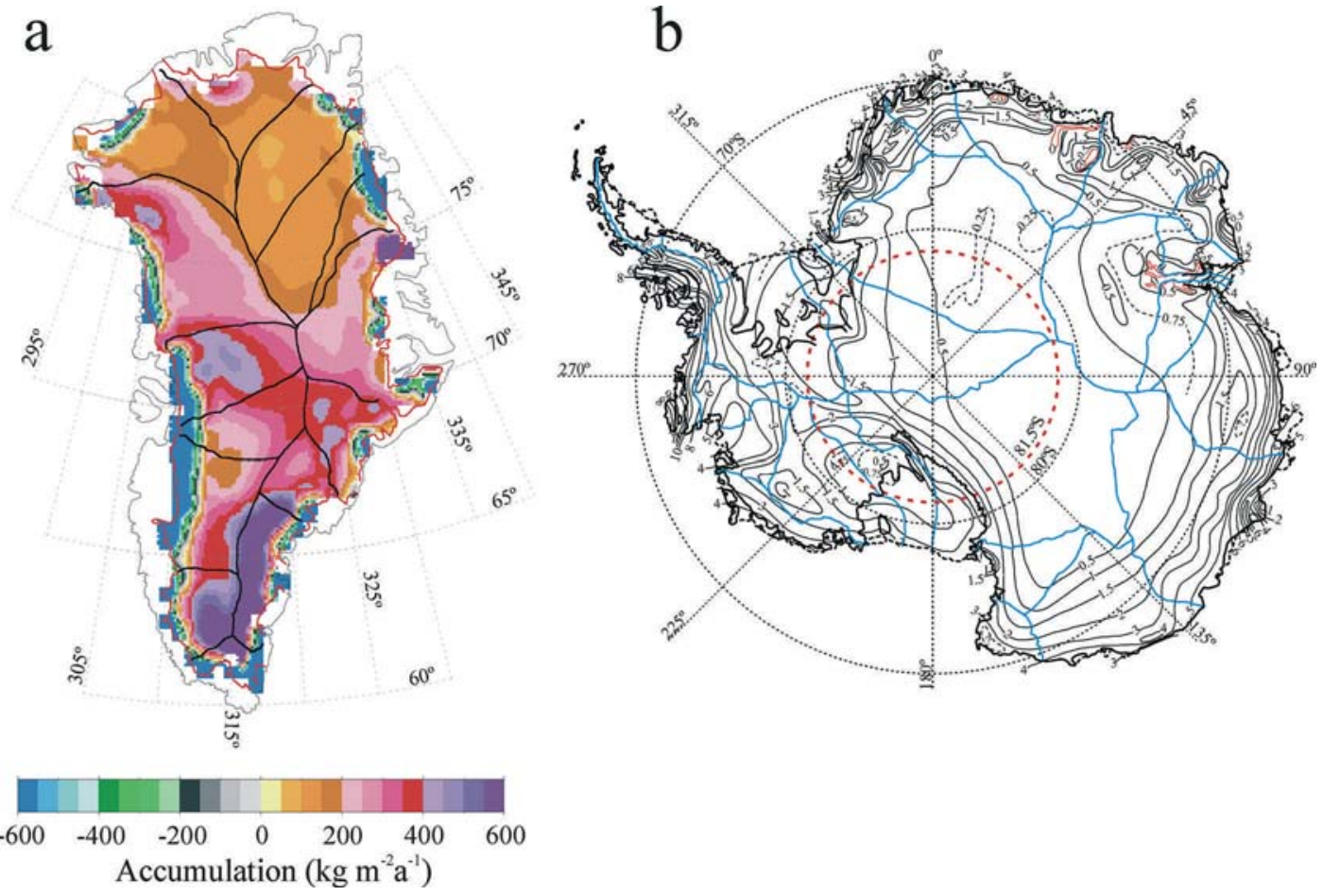

Fig. 10. Distribution of net accumulation at the surface based on compiled data. (a) Surface balance rate on Greenland determined for gridpoints (i) by analysis of firn emissivity in the area above the intra-percolation line compared with pit and core data at stations and along traverse routes, bulk corresponding to strata accumulated $\sim 1950-80$, and (ii) by accumulation/ablation models output below the intrapercolation line (Zwally and Giovinetto, 2000, 2001). (b) Isopleths map of surface balance for Antarctica (in $\times 100 \mathrm{~kg} \mathrm{~m}^{-2} \mathrm{a}^{-1}$ ) drawn on the basis of field data from pits, cores and stake networks at stations and along traverse routes, bulk corresponding to strata accumulated 1950-2000 (Giovinetto and Zwally, 2000, updated). 
a

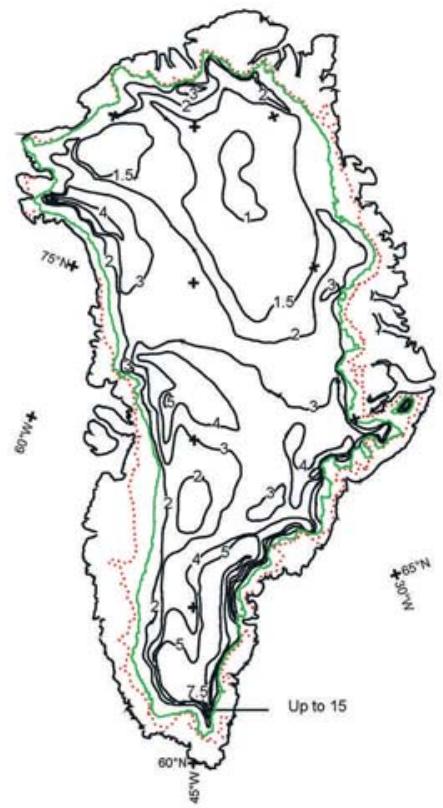

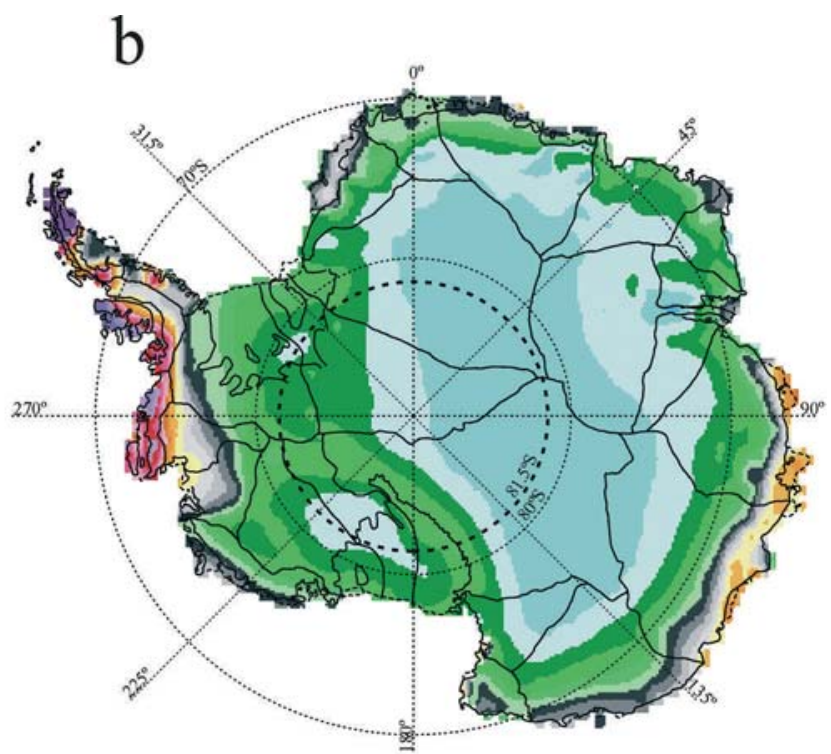

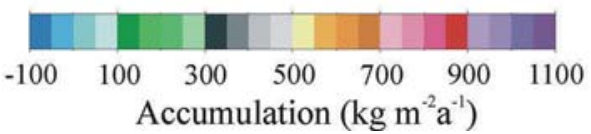

Fig. 11. Distribution of net accumulation at the surface interpolated from compilations of field data and models output. (a) Isopleths map of surface balance on Greenland (in $\times 100 \mathrm{~kg} \mathrm{~m}^{-2} \mathrm{a}^{-1}$ ) drawn on the basis of the grid values shown in Figure 10a (Zwally and Giovinetto, 2001, modified). (b) Surface balance rate on Antarctica determined for gridpoints by interpolation from the isopleths pattern shown in Figure 10b (Giovinetto and Zwally, 2000, updated).

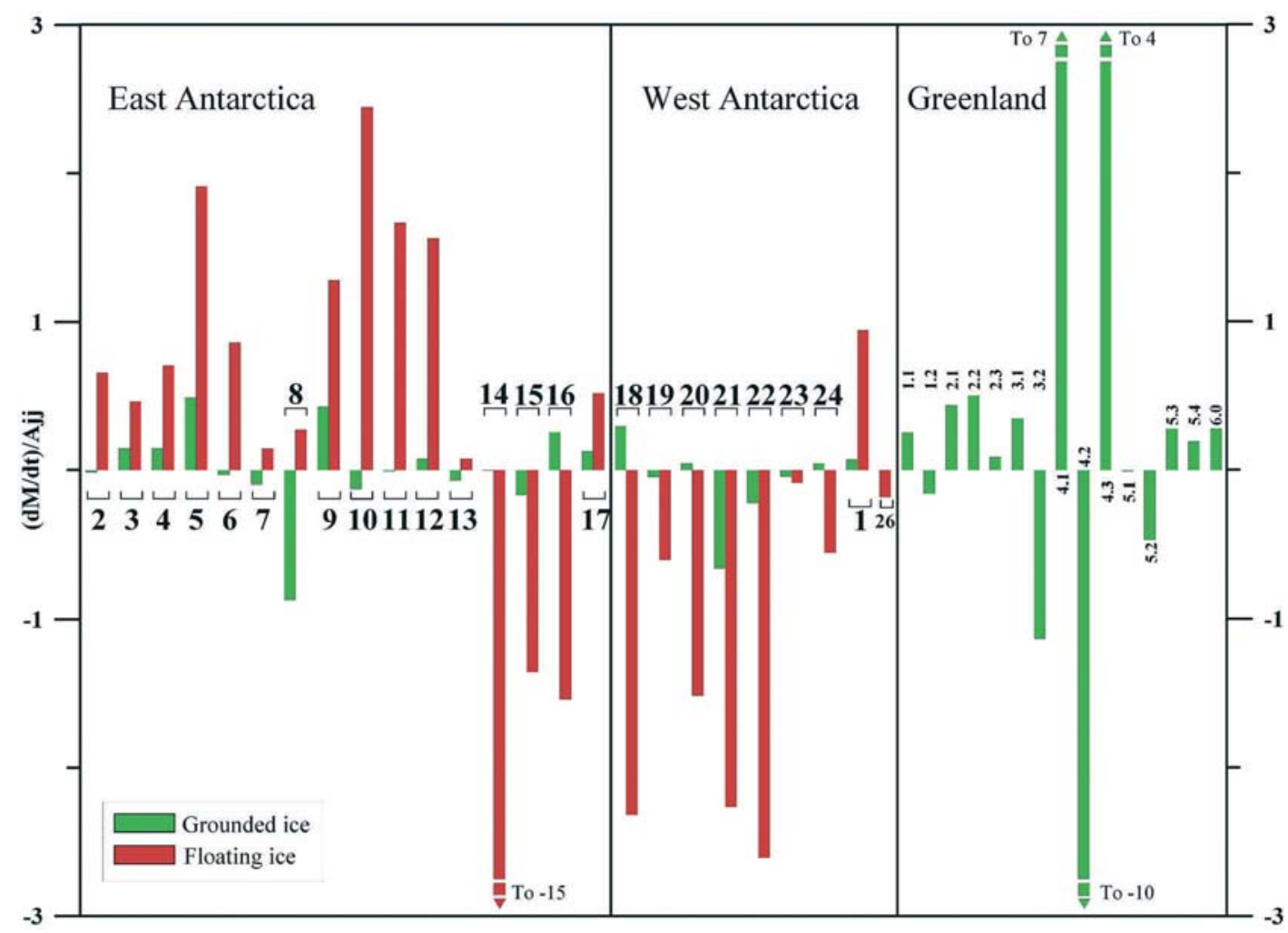

Fig. 12. Distribution of the ratio between net mass budget and net surface accumulation in the grounded-ice and floating-ice areas of each drainage system of Antarctica and Greenland, as listed in Table 2 (column $(\mathrm{d} M / \mathrm{d} t) / A_{j j}$ ). In Antarctica the estimated gains and losses are smaller than $\pm 50 \%$ of the accumulation in 22 of the grounded-ice entities of the 24 systems included in the study, or $97 \%$ of their total area, and smaller than $\pm 100 \%$ in 13 of the floating-ice entities of the 25 systems included in the study, or $58 \%$ of their total area. In Greenland the gains and losses are smaller than $\pm 50 \%$ of the accumulation in 11 of the 15 systems included in the study, or $83 \%$ of their total area. 